\title{
Economics
}

HEI Working Paper No: 04/2004

\section{Inflation Targeting and Exchange Rate Pass-Through}

\author{
Alessandro Flamini \\ Graduate Institute of International Studies
}

(C) The Authors.

All rights reserved. No part of this paper may be reproduced without the permission of the authors. 


\title{
Inflation Targeting and Exchange Rate Pass-through*
}

\author{
Alessandro Flamini ${ }^{\dagger}$ \\ Graduate Institute of International Studies \\ First draft: June 2004 \\ This version: April 2005
}

\begin{abstract}
This paper analyzes how endogenous imperfect exchange rate pass-through affects inflation targeting optimal monetary policies in a New Keynesian small open economy. The paper shows that an inverse relation exists between the passthrough and the insulation of the economy from foreign and monetary policy shocks, and that imperfect pass-through tends to decrease the variability of the terms of trade. Furthermore, with CPI inflation targeting, in the short run, delayed pass-through constrains monetary policy more than incomplete passthrough and interest rate smoothing amplifies this effect. When the pass-through decreases, the variability in economic activity tends to raise and the trade-off between the stabilization of CPI inflation and output worsens in direct relation to how strictly the central bank is targeting CPI inflation. In contrast, with domestic inflation targeting, optimal monetary policy is not constrained and opposite results occur. Consequently, imperfect pass-through favors the choice of domestic to CPI inflation targeting.
\end{abstract}

JEL Classification: E52, E58, F41.

Key Words: Inflation Targeting; Exchange Rate Pass-through; Small openeconomy; Direct Exchange Rate Channel; Optimal Monetary Policy.

\section{Introduction}

What is the appropriate monetary policy response to domestic and foreign shocks with imperfect exchange rate pass-through? How does incomplete or delayed passthrough affect the efficiency of the monetary policy and the volatility of the economy? What measure of inflation should a central bank target considering different types of pass-through? In the last few years this type of questions has prompted an increase of interest in the relationship between the pass-through of the exchange rate and

\footnotetext{
*This paper has been partly prepared during my visit at Princeton University, January-May 2003 and partly during my stay at the Graduate Institute of International Studies of Geneva. I thank Charles Wyplosz and Lars Svensson for valuable discussions, hindsight and encouragement and an anonymous referee for useful and detailed comments. I thank Hans Genberg, Alexander Swoboda and Michael Woodford for useful discussions and suggestions. I have also benefited from comments from Gianluca Benigno, Andrea Fracasso and Roman Marimon and the participants to seminars at the Graduate Institute of International Studies, the London School of Economics, the Ente Einaudi, and the XIII international "Tor Vergata" conference on Banking and Finance. Any errors are my own. Financial support from Ente 'Luigi Einaudi' and Princeton University is gratefully acknowledged.

${ }^{\dagger}$ E-mail: flamini8@hei.unige.ch
} 
the working of the economy ${ }^{1}$. This interest is supported by several empirical works spanning over two decades and differing for the countries and the industries considered which provide evidence on imperfect pass-through ${ }^{2}$.

The pass-through of costs to import price is a complex mechanism, and several factors may play a role in its determination. The positive correlation between inflation and inflation persistence, and the positive impact of the expectations of inflation persistence on the pass-through (via the Taylor staggered price-setting behavior), establish a positive relation from inflation to the degree of pass-through (Taylor, 2000). Also, the firm's strategy of the pricing to market (PTM) based on international market segmentation and local currency pricing (LCP) leads to incomplete pass-through (Betts and Devereux, 2000). ${ }^{3}$ Furthermore, the presence of shipping costs and nontraded distribution services as well as intermediary firms between the exporters and the consumers is likely to reduce the pass-through more (Mc Callum and Nelson (1999), Obstfeld and Rogoff (2000)).

Taking these factors into account, it has been possible to obtain interesting results on the relation between the pass-through and the optimal monetary policy ${ }^{4}$.

In a New Keynesian perspective, considering an emerging market economy with nominal rigidities in both the non-traded goods and import sectors, Devereux, Lane and $\mathrm{Xu}$ (2004) show that in the case of complete pass-through, non-tradable inflationtargeting dominates CPI inflation-targeting and an exchange rate peg while, in the case of delayed pass-through, CPI inflation-targeting performs better. Devereux (2001) considers a small open-economy with sticky prices in the non-traded goods and import sectors and compares the Taylor rule, a rule that stabilizes non-traded goods inflation, strict CPI inflation-targeting and a rule which pegs the exchange rate. He finds that in general, with delayed pass-through, the trade-off between output and inflation variability is less pronounced; the best monetary policy stabilizes non-traded goods price inflation; and strict CPI inflation-targeting performs better with partial pass-through. Smets and Wouters (2002) present a small openeconomy model calibrated to euro area data with nominal rigidities in the domestic and imported goods sectors. In this framework, they consider that the welfare costs determined by nominal rigidities in the imported goods sector depend positively on the exchange rate variability. Consequently, they make the point that with delayed pass-through, output-gap stabilization is constrained by the minimization of these

\footnotetext{
${ }^{1}$ The expression "exchange rate pass-through" denotes the transmission of a change in import costs to the domestic prices of imported goods.

${ }^{2}$ For example, Krugman (1987) considering US import data in the period 1980-1983 finds that, in the machinery and transport sector, 35 to 40 percent of the appreciation of the dollar was not reflected in a decrease of the import prices. Knetter (1989) finds that for the period 1977-1985 US export prices in the destination market currency tend to be either insensitive to exchange rate fluctuations or tend to amplify their impact, while German export prices tend to stabilize the exchange rate fluctuations. Considering the sample period 1974-1987, Knetter (1993) shows that Japanese export price adjustments in the destination country currency offset 48 percent of the exchange rate fluctuations while for U.K. and German export prices this fraction reaches 36 percent. More recently, Campa and Goldberg's (2002) estimation for the period 1975-1999 and a sample of OECD countries supported the complete pass-through hypothesis for the long run but not for the short run.

${ }^{3} \mathrm{LCP}$, in turn, has been justified in two ways: by a low market share of the exporter country in the foreign market coupled with a low degree of differentiation of its goods (Bacchetta and Wincoop, 2002) and by a greater monetary policy stability of the importing country compared to that of the exporting country (Devereux and Engel, 2001 and Devereux et al., 2004).

${ }^{4}$ See also Lane and Ganelli (2002) for a survey of the implications of different degrees of passthrough when the currency denomination of assets contracts is taken into account.
} 
welfare costs because it leads to larger exchange rate variability.

In a New Classical perspective, Corsetti and Pesenti (2004) show the importance of the degree of pass-through in affecting the trade-off between output-gap stabilization and import costs, and the implication for the optimal monetary policy. When the pass-through is incomplete because of LCP, exporters' profits oscillate with the exchange rate, and the hedging behavior of the exporters consequently links the import prices positively to the variability of the exchange rate. Then, if the monetary policy aims to stabilize the output-gap, it will increase the variability of the exchange rate and the import prices. Hence, optimal monetary policy has to equate at the margin the cost of the output-gap with the cost of a higher import price. It follows that the lower the pass-through, the lower the socially optimal output-gap stabilization ${ }^{5}$.

These models employ a welfare optimization approach to determine the monetary policy while considering either delayed or incomplete pass-through. The present study differs from the previous models because embeds into the New Keynesian framework (i) inflation-forecast targeting, which is the procedure followed by inflation-targeting central banks ${ }^{6}$; (ii) a more sophisticated transmission mechanism with stylized realistic lags for various channels; and (iii) both incomplete and delayed pass-through. All these features are critical to analyze real world monetary policy. As noted by Svensson $(2003,2005)$, a maximizing welfare approach is not operational, in contrast to inflation-targeting. Also, a realistic transmission mechanism is important because it allows addressing a main difficulty of monetary policy: the large gap between goals and instrument. Finally, considering only one type of imperfect pass-through could be misleading in the understanding of the transmission mechanism and the actual latitude of the monetary policy.

The motivating idea of this work is that the type and degree of pass-through affects the projections of the economy, whose accurate determination is crucial for central banks that pursue inflation-targeting. The reasoning is the following. Optimal monetary policy employs all its transmission channels according to their relative efficiency. These channels feature different transmission lags, however, in open economies one particular channel is considered to have no lag, whence comes the name of Direct Exchange Rate Channel (henceforth DERC). Due to this quality, the DERC allows monetary policy to affect current CPI inflation and according to the conventional view, and as it is shown in Ball (1998) and Svensson (2000), this channel plays a prominent role in the transmission of monetary policy. Yet, the DERC is considered in these papers with the strict assumption of perfect pass-through. Since imperfect pass-through affects the efficiency of the DERC and its interaction with the other channels, it affects also the optimal use of all the transmission channels. Thus, the type and degree of pass-through affects the dynamics of the economy and the projections of the macrovariables, which in turn are crucial with the inflation-forecast targeting procedure.

The main purpose of this study is to build a simple but reasonably general model

\footnotetext{
${ }^{5}$ On the relationship between welfare, exchange rate volatility and incomplete pass-through in a similar perspective, see also Sutherland (2005).

${ }^{6}$ The procedure of inflation-forecast targeting consists of first determining the projections for inflation (and output) conditional to all the information available and the monetary policy, and then chosing the monetary policy that allows the projections to be equal to the targets at a certain time horizon, or more realistically, that determines a desired path for the projections. See Svensson (1997) and (1998b).
} 
to compare different inflation-targeting monetary policies and related responses of the economy to shocks with endogenous incomplete and/or delayed pass-through. The analysis is based on a dynamic stochastic general equilibrium model built upon Svensson's (2000) model.

This model deviates from Svensson's (2000) in two ways. 1. It provides complete microfoundations, in particular concerning inertia in the aggregate supply and demand relations following Christiano et al. (2001) and Abel (1990), respectively. 2. It includes two interacting sectors: a domestic sector that produces and retails domestic goods and an import sector which only retails foreign goods. These sectors are connected because the domestic one uses as intermediate goods its own goods and the import goods while the import sector uses foreign and domestic goods.

The latter sector is similar to the import sector in Smets and Wouters (2002) in that it derives delayed pass-through from the sticky price assumption modeled in the style of Calvo (1983). It is also similar to McCallum and Nelson (1999), Burstein, Neves and Rebelo (2003) and Corsetti and Dedola (2004), in that local inputs may be required to bring the foreign goods to domestic consumers; as a result, when this is the case, foreign goods are intermediate goods in the production of the import goods and the pass-through turns out to be incomplete.

This is a notable feature of the model because it allows us to consider either foreign goods as intermediate goods in the domestic sector but final goods in the import sector or as intermediate goods in both the domestic and import sectors. An interest in the latter case is motivated by the finding of Kara and Nelson (2002), who show that modelling imports as intermediate goods leads to an aggregate supply which delivers the best approximation of the exchange rate/consumer price relationship.

Such flexibility in the degree of delay and completeness of the pass-through allows a better understanding of the relation between the various exchange rate channels and the transmission mechanism of the monetary policy. Specifically, it illustrates how the pass-through affects the optimal use of all the transmission channels.

A key feature of this model is that it derives structural relations for all the agents in the economy. In particular, the central bank follows a specific targeting rule which, as it has been shown by Svensson (2003), is equivalent to the equilibrium condition equating the marginal rate of substitution and transformation between the loss function variables. The model determines this rule assuming that the central bank minimizes in each period its intertemporal loss function under discretion, i.e. taking the expectations of the private sector as given and knowing that it will reoptimize in the subsequent periods. Thus the model looks for the Nash equilibrium in the game between the central bank and the private sector, which turns out to be characterized by a time-invariant reaction function for the central bank.

Within this framework the present study addresses some issues that have been neglected in the literature. First, it analyzes the way in which the pass-through affects the working of the DERC and examines to what extent this latter channel is reliable for the transmission of the monetary impulse in the short run. Such an analysis is important, as this channel is considered to be the only one available to stabilize CPI inflation in the short run.

Second, it considers that the DERC is also one of the avenues through which shocks originating in the foreign sector propagate to CPI inflation. Indeed, a shock in foreign output or inflation affects the foreign interest rate, which in turn propagates to the exchange rate via the interest rate parity condition, finally hitting CPI inflation. 
Thus, the second question addressed is how the way in which the pass-through occurs affects the degree of insulation of the economy from foreign shocks.

Third, the paper investigates the impact of imperfect pass-through on the volatility of the economy and on the choice of the inflation target.

With regard to inflation-targeting effectiveness, the analysis shows that the type and degree of imperfect pass-through affect the capacity of the central bank to stabilize in the short run CPI inflation but not domestic inflation. More specifically, delayed pass-through turns out to reduce monetary policy effectiveness more than incomplete pass-through. Yet, similarly to domestic inflation-targeting, in the medium run, imperfect pass-through constrains less CPI inflation-targeting.

In relation to the volatility of the economy, this study indicates that imperfect pass-through decreases the variability of the terms of trade and, with CPI inflationtargeting, tends to increase the variability of the economy. Consequently, this study suggests that it may be better to target domestic inflation with incomplete and delayed pass-through.

The model also shows that, with CPI inflation-targeting, imperfect pass-through increases the trade-off between CPI inflation and output-gap variabilities, and that this phenomenon is stronger the more monetary policy is concerned with CPI inflation versus output-gap stabilization. Thus, it is important to know the type and degree of the pass-through to assess the attainable trade-off between the variability of the output-gap and CPI inflation.

Finally, interest smoothing constrains the ability of the central bank to stabilize CPI and domestic inflation in the short run.

The remainder of the paper is organized as follows: section 2 presents the model. Section 3 analyzes the optimal monetary policy; in particular, the reaction functions corresponding to different types of inflation-targeting and pass-through and the impulse response functions to some domestic and foreign shocks. Section 4 focuses on the relation between the pass-through, the volatility of the economy and the choice of the inflation measure to target. Section 5 concludes and suggests some directions for further research. Appendix A and B present some details of the microfoundations of the model and its state-space form.

\section{The model}

The model describes a small open economy related to an exogenous rest of the world. All the equations for the domestic economy are structural relations derived from equilibrium conditions that characterize optimal private and public sector behaviors. In order to focus the analysis on the main features of the monetary transmission mechanism, I follow Woodford (2003) in considering a "cashless" economy".

\subsection{The household}

The economy is populated by a continuum of unit mass of consumers/producers indexed by $j \in[0,1]$ sharing the same preferences and living forever. Intertemporal utility for the representative agent is given by

\footnotetext{
${ }^{7}$ Woodford (2003) shows that, in general, abstracting from monetary frictions has a minor impact on the working of the economy.
} 


$$
E_{t} \sum_{\tau=0}^{\infty} \delta^{\tau} U\left(C_{t+\tau}, \check{C}_{t+\tau-1}\right),
$$

where $\delta$ is the intertemporal discount factor, $C_{t}$ is total consumption of consumer $j$, and $\check{C}_{t}$ is the total aggregate consumption. Preferences over total consumption feature habit formation which is modeled in the style of Abel (1990) by the following instantaneous utility function

$$
U\left(C_{t+\tau}, \check{C}_{t+\tau-1}\right)=\left\{\begin{array}{cc}
\frac{\left(C_{t+\tau} / \check{C}_{t+\tau-1}^{\widetilde{\nu}}\right)^{1-\frac{1}{\sigma}}}{1-\frac{1}{\sigma}} & \sigma \neq 1 \\
\ln \left(C_{t+\tau} / \check{C}_{t+\tau-1}^{\widetilde{v}}\right) & \sigma=1
\end{array}\right\},
$$

where $\widetilde{\nu} \geq 0$ captures the willingness to "keep up with the Joneses" and $\sigma>0$ is the intertemporal elasticity of substitution. This assumption is motivated by the results of Fuhrer (2000) and Banerjee and Batini (2003) which show the importance of habit formation in explaining the inertia in consumption decisions, consequently improving the empirical fit of the sticky prices open economy model.

For sake of simplicity, labor is absent from the preferences of the consumer/producer captured by $(1)^{8}$. Yet, as it will be shown later, production implies disutility for the consumer in the form of less consumption available. Indeed, consumption goods are also intermediate goods used in production. Furthermore, since the input requirement function is convex ${ }^{9}$, more production implies a smaller share of goods available for consumption. Thus, the utility function (1) can be interpreted as the utility of the yeoman farmer which is increasing and concave in consumption and decreasing and convex in production.

Total consumption, $C_{t}$, is a CES aggregate of two subindices for consumption of the domestic good, $C_{t}^{d}$, and import good, $C_{t}^{i}$,

$$
C_{t} \equiv\left[(1-w) C_{t}^{d^{1-\frac{1}{\theta}}}+w C_{t}^{i^{1-\frac{1}{\theta}}}\right]^{\frac{\theta}{\theta-1}},
$$

where $\theta$ is the intratemporal elasticity of substitution between domestic and import goods and it is assumed equal to one following Corsetti and Pesenti $(2004)^{10}, w$ determines the steady state share of imported goods in total consumption and $C_{t}^{d}$, $C_{t}^{i}$ are Dixit-Stiglitz aggregates of continuum of differentiated domestic goods and import goods (henceforth indexed with $d$ and $i$ respectively),

$$
C_{t}^{h}=\left[\int\left(C_{t}^{h}(j)\right)^{1-\frac{1}{\vartheta}} d j\right]^{\frac{1}{1-\vartheta}}, \quad h=d, i,
$$

where $\vartheta>1$ is the elasticity of substitution between any two differentiated goods and, for sake of simplicity, is the same in both sectors.

The flow budget constraint for consumer $j$ in any period $t$ is given by

$$
\frac{B_{t}}{1+I_{t}}+\frac{B_{t}^{*}}{1+I_{t}^{*}} S_{t}+P_{t}^{c} C_{t}=B_{t-1}+B_{t-1}^{*} S_{t}+D_{t}^{d}+D_{t}^{i}
$$

\footnotetext{
${ }^{8}$ Another example of similar preferences is in Svensson (2000).

${ }^{9}$ The input requirement function is convex because the production function is assumed to be concave. This assumption, in turn, can be motivated by constant capital.

${ }^{10}$ This assumption ensures the stationarity of the model.
} 
where $B$ and $B^{*}$ are two international bonds issued on a discount basis and denominated in domestic and foreign currency with interest rates $I_{t}$ and $I_{t}^{*}$ respectively, $S_{t}$ is the nominal exchange rate, expressed as home currency per unit of foreign currency. $D_{t}^{d}$ and $D_{t}^{i}$ are the dividends distributed by the domestic and the import sector and, finally, $P^{c}$ is the overall Dixit-Stiglitz price index for the minimum cost of a unit of $C_{t}$ and is given by

$$
P_{t}^{c}=\left[(1-w) P_{t}^{d^{(1-\theta)}}+w P_{t}^{i^{(1-\theta)}}\right]^{\frac{1}{1-\theta}},
$$

with $P^{d}, P^{i}$ denoting, respectively, the Dixit-Stiglitz price index for goods produced in the domestic and import sector.

To rule out "Ponzi schemes", I assume that in any period $t$ the consumer chooses the value of the portfolio in $t+1$ such that his borrowing is no larger than the present value of all future dividends

$$
B_{t+1}+B_{t+1}^{*} S_{t+1} \geq-\sum_{T=t+1}^{\infty}\left(1+I_{T}\right)^{-1}\left(D_{T}^{d}+D_{T}^{i}\right),
$$

and that the present value of future dividends is finite.

Utility maximization subject to the budget constraint and the limit on borrowing gives the Euler equation and the uncovered interest rate parity, respectively

$$
\begin{gathered}
c_{t}=\beta c_{t-1}+(1-\beta) c_{t+1 \mid t}-(1-\beta) \sigma\left(i_{t}-\pi_{t+1 \mid t}^{c}\right), \quad \beta \equiv \frac{\widetilde{\nu}(1-\sigma)}{1+\widetilde{\nu}(1-\sigma)}<1, \\
i_{t}-i_{t}^{*}=s_{t+1 \mid t}-s_{t},
\end{gathered}
$$

where for any variable $x$, the expression $x_{t+\tau \mid t}$ stands for the rational expectation of that variable in period $t+\tau$ conditional on the information available in period $t$ and, by means of a $\log$-linearization, the variables $c_{t}, \pi_{t}^{c}, i_{t}, i_{t}^{*}$ and $\left(s_{t+1 \mid t}-s_{t}\right)$ are $\log$ deviations from their respective constant steady state values; finally, $c_{t}$ denotes total aggregate consumption, obtained considering that in equilibrium total consumption for agent $j$ is equal to total aggregate consumption, i.e. $C_{t}=\check{C}_{t}$, and $\pi_{t}^{c}$ denotes CPI inflation (measured as the log deviation of gross CPI inflation from the constant CPI inflation target).

\subsubsection{Domestic consumption of goods produced in the domestic sector}

Preferences captured by equation (2) imply that the (log deviation of the) domestic demand for goods produced in the domestic sector, $c_{t}^{d}$, is given by

$$
c_{t}^{d}=c_{t}-\theta\left(p_{t}^{d}-p_{t}^{c}\right)
$$

which, considering the (log-linearized version of the) price index equation (3), can be rewritten as

$$
c_{t}^{d}=c_{t}+w \theta q_{t},
$$

where $q_{t} \equiv p_{t}^{i}-p_{t}^{d}$ is the terms of trade.

Then, solving equation (4) for $c_{t}$ and combining it with equation (6) I obtain

$$
c_{t}^{d}=-\sigma\left(1-F_{1} L\right)^{-1} \rho_{t}-\sigma\left(1-F_{1} L\right)^{-1} w q_{t}+\theta w q_{t},
$$


where $F_{1}<1$ is the smaller root of the characteristic polynomial of equation (4) and

$$
\rho_{t} \equiv \sum_{\tau=0}^{\infty}\left(i_{t+\tau \mid t}-\pi_{t+\tau+1 \mid t}^{d}\right)
$$

can be interpreted as the long real interest rate ${ }^{1112}$.

\subsubsection{Aggregate demand for goods produced in the domestic sector}

Total aggregate demand for the good produced in the domestic sector is

$$
\widehat{Y}_{t}^{d}=C_{t}^{d}+Y_{t}^{d, d}+Y_{t}^{d, i}+C_{t}^{* d}
$$

where $Y_{t}^{d, d}, Y_{t}^{d, i}$ and $C_{t}^{* d}$ denote the quantity of the (composite) domestic good which is used as an input in the domestic sector, as an input in the import sector and which is demanded by the foreign sector, respectively.

To specify the quantities of the (composite) domestic good which are used as an input in the domestic and import sector, it is convenient to describe here the production technologies. I assume that both sectors share the same Leontief technology and each one features a continuum of unit mass of firms, indexed by $j$, that produce differentiated goods $Y_{t}^{d}(j)$ and $Y_{t}^{i}(j)$ in the domestic and import sector respectively. Furthermore, I assume that sectors differ for the input used: the domestic sector uses a composite input consisting of the domestic (composite) good itself and the (composite) import good produced in the import sector; the import sector uses a composite input consisting of the foreign good $Y_{t}^{*}$ and the domestic (composite good). Thus the production functions in the domestic and import sector are given respectively by

$$
Y_{t}^{d}(j)=f\left[A_{t}^{d} \min \left\{\frac{Y_{t}^{d, d}}{1-\mu}, \frac{Y_{t}^{i, d}}{\mu}\right\}\right], \quad Y_{t}^{i}(j)=f\left[A_{t}^{i} \min \left\{\frac{Y_{t}^{*}}{1-\mu^{i}}, \frac{Y_{t}^{d, i}}{\mu^{i}}\right\}\right],
$$

where $f$ is an increasing, concave, isoelastic function, $A_{t}$ is an exogenous (sector specific) economy-wide productivity parameter, $\mu, \mu^{i} \in[0,1],(1-\mu)$ and $\mu$ denote, respectively, the shares of domestic good and import good in the composite input required to produce the differentiated domestic good $j$, and $\left(1-\mu^{i}\right)$ and $\mu^{i}$ denote, respectively, the shares of foreign good and domestic good in the composite input required to produce the differentiated import good $j$.

Thus the quantities of the (composite) domestic good used as an input in the domestic and import sector are

$$
\begin{gathered}
Y_{t}^{d, d}=\frac{1}{A_{t}^{d}}(1-\mu) f^{-1}\left(\widehat{Y}_{t}^{d}\right), \\
Y_{t}^{d, i}=\frac{1}{A_{t}^{i}} \mu^{i} f^{-1}\left(\widehat{Y}_{t}^{i}\right),
\end{gathered}
$$

where $\widehat{Y}_{t}^{i}$ denotes the demand of the import good. Finally, log-linearizing equation (9) around the steady state values yields

\footnotetext{
${ }^{11}$ Under the expectations hypothesis and considering a zero-coupon bond with a finite maturity, the variable $\rho_{t}$ is approximately the product of the long real bond rate and its maturity; for further discussion see Svensson (2000).

${ }^{12}$ Details on the derivation of equation (7) are in the appendix.
} 


$$
\widehat{y}_{t}^{d}=\kappa_{1}\left(\mu^{i}\right) c_{t}^{d}+\kappa_{2}\left(\mu^{i}\right) \widehat{y}_{t}^{i}+\kappa_{3}\left(\mu^{i}\right) c_{t}^{* d},
$$

where $\kappa_{1}^{\prime}\left(\mu^{i}\right), \kappa_{3}^{\prime}\left(\mu^{i}\right)<0$ and $\kappa_{2}^{\prime}\left(\mu^{i}\right)>0$, (see the appendix for details).

Next, I assume, as in Svensson (2000), that $c_{t}^{* d}$ is exogenous and given by

$$
\begin{aligned}
c_{t}^{* d} & =c_{t}^{*}+\theta^{*} w^{*} q_{t} \\
& =\bar{\beta}_{y}^{*} y_{t}^{*}+\theta^{*} w^{*} q_{t},
\end{aligned}
$$

where $c_{t}^{*}$ denotes $(\log )$ foreign real consumption, $\theta^{*}$ and $w^{*}$ denote, respectively, the foreign atemporal elasticity of substitution between domestic and foreign goods and the share of domestic goods in foreign consumption. Furthermore, I define the output-gap in the domestic sector $y_{t}^{d}$ as

$$
y_{t}^{d} \equiv \widehat{y}_{t}^{d}-y_{t}^{d, n},
$$

where $y_{t}^{d, n}$ denotes the $\log$ deviation of the natural output in the domestic sector from its steady state value, and I assume that in both sectors the log-deviation of the natural output from its steady state value is exogenous, stochastic and follows

$$
y_{t+1}^{h, n}=\gamma_{y}^{h, n} y_{t}^{h, n}+\eta_{t+1}^{h, n}, \quad 0 \leq \gamma_{y}^{h, n}<1, \quad h=d, i
$$

where $\eta_{t+1}^{h, n}$ is a serially uncorrelated zero-mean shock to the natural output level. Finally, in line with the central banks' view of the approximate one-period lag necessary to affect aggregate demand, I assume that consumption decisions are predetermined one period in advance and obtain the aggregate demand in the domestic sector in terms of the output-gap

$$
y_{t+1}^{d}=\beta_{y} y_{t}^{d}-\beta_{\rho} \rho_{t+1 \mid t}+\beta_{q} q_{t+1 \mid t}-\beta_{q_{-1}} q_{t}+\beta_{y^{*}} y_{t}^{*}+\beta_{y^{n}} y_{t}^{d, n}+\eta_{t+1}^{d}-\eta_{t+1}^{d, n}
$$

where $\eta_{t+1}^{d}$ is a serially uncorrelated zero-mean demand shock. In (15) all the coefficients are positive and functions of the structural parameters of the model.

\subsubsection{Consumption and aggregate demand of goods produced in the im- port sector}

Considering equation (2), the (log-deviation of) consumption of goods produced in the import sector, $c_{t}^{i}$, is given by

$$
\begin{aligned}
c_{t}^{i} & =c_{t}-\theta\left(p_{t}^{i}-p_{t}^{c}\right) \\
& =c_{t}-\theta(1-w) q_{t},
\end{aligned}
$$

and following the same derivation used for the $\mathrm{AD}$ in the domestic sector yields

$$
c_{t}^{i}=-\sigma\left(1-F_{1} L\right)^{-1} \rho_{t}-\sigma\left(1-F_{1} L\right)^{-1} w q_{t}-\theta(1-w) q_{t} .
$$

Aggregate demand for import goods is given by

$$
\widehat{Y}_{t}^{i}=C_{t}^{i}+Y_{t}^{i, d}
$$


where $Y_{t}^{i, d}$ denotes the amount of the import good used as an input in the domestic sector. Considering the technology in (10), this quantity is given by

$$
Y_{t}^{i, d}=\mu \frac{1}{A_{t}^{d}} f^{-1}\left(\widehat{Y}_{t}^{d}\right) .
$$

Log-linearizing (18) around the steady state results in

$$
\widehat{y}_{t}^{i}=(1-\widetilde{\kappa}) c_{t}^{i}+\widetilde{\kappa} \widehat{y}_{t}^{d} .
$$

Finally, the same assumptions used to derive the aggregate demand for the domestic sector goods yield

$$
y_{t+1}^{i}=\beta_{y} y_{t}^{i}-\beta_{\rho}^{i} \rho_{t+1 \mid t}-\beta_{q}^{i} q_{t+1 \mid t}+\beta_{q_{-1}}^{i} q_{t}+\beta_{y^{*}}^{i} y_{t}^{*}+\beta_{y^{n}}^{i} y_{t}^{i, n}+\eta_{t+1}^{d}-\eta_{t+1}^{d, n},
$$

where all the coefficients are positive and depend on the structural parameters of the model and $\eta_{t+1}^{i}$ is a serially uncorrelated zero-mean demand shock.

Summing up, aggregate demands in both sectors in period $t+1$ are based on the information available in period $t$, because of the assumption of predetermined expenditure decisions. Due to the use of the output produced in the other sector as an input, they depend also on the demand in the other sector. Due to the assumptions of habit formation in consumption, they depend on the previous aggregate demands ${ }^{13}$. Furthermore, by setting the sequence of expected short nominal interest rates, i.e. $\left\{i_{t+\tau \mid t}\right\}_{\tau=0}^{\infty}$, the central bank affects the long interest rate defined in equation (8) which, in turn, affects the output gap. This is the aggregate demand channel. Finally, a first exchange rate channel, which consists of switching the demand between domestic and foreign goods, is captured here by the terms of trade.

\section{$2.2 \quad$ Firms}

In both sectors, aggregate supply is derived according to the Calvo (1983) staggered price model and inflation inertia is introduced as indicated by Christiano et al. (2001) and also by the presence of the terms of trade. Beyond the use of different inputs, the two sectors have different firm decision timing.

\subsubsection{Domestic sector}

In the domestic sector, the representative consumer/producer $j$ produces the variety $j$ of the domestic good, $Y_{t}^{d}(j)$, with a composite input whose price is $W_{t}$. Since all the varieties use the same technology, there is a unique input requirement function for all $j$ given by $\frac{1}{A_{t}^{d}} f^{-1}\left[Y_{t}^{d}(j)\right]$ and the variable cost of producing the quantity $Y_{t}^{d}(j)$ is $W_{t} \frac{1}{A_{t}^{d}} f^{-1}\left[Y_{t}^{d}(j)\right]$. Furthermore, since there is a Dixit-Stiglitz aggregate of domestic goods, the demand for variety $j$ is

$$
Y_{t}^{d}(j)=\widehat{Y}_{t}^{d}\left(\frac{P_{t}^{d}(j)}{P_{t}^{d}}\right)^{-\vartheta},
$$

\footnotetext{
${ }^{13}$ As it has been noted by Benigno (2004), the presence of the terms of trade introduces furter inertia. Indeed, from the definition of the terms of trade it follows that

$$
q_{t+\tau \mid t}=q_{t+\tau-1 \mid t}+\pi_{t+\tau \mid t}^{i}-\pi_{t+\tau \mid t}^{d}, \quad \forall \tau \geq 0 .
$$
}


where $P_{t}^{d}(j)$ is the nominal price for variety $j$ and $\vartheta$ is the elasticity of substitution between different varieties. As shown in equation (10), the composite input is a convex combination of both aggregates of domestic and import goods (with price $P_{t}^{i}$ and which will be described below). Thus the price of the input is given by $W_{t} \equiv(1-\mu) P_{t}^{d}+\mu P_{t}^{i}$.

Then, I assume (i) that the consumer/producer chooses in any period the new price with probability $(1-\alpha)$ or keeps the previous period price indexed to past inflation with probability $\alpha$, and (ii) that the price at period $t+g$ is chosen $g$ periods in advance. It follows that the decision problem for firm $j$ at time $t$ is

$$
\begin{aligned}
& \max _{\widetilde{P}_{t+g}^{d}} E_{t} \sum_{\tau=0}^{\infty} \alpha^{\tau} \delta^{\tau} \widetilde{\lambda}_{t+\tau+g}^{d}\left\{\frac{\widetilde{P}_{t+g}^{d}\left(\frac{P_{t+\tau+g-1}^{d}}{P_{t+g-1}^{d}}\right)^{\zeta}}{P_{t+g+\tau}^{d}} \widehat{Y}_{t+\tau+g}^{d}\left[\frac{\widetilde{P}_{t+g}^{d}\left(\frac{P_{t+\tau+g-1}^{d}}{P_{t+g-1}^{d}}\right)^{\zeta}}{P_{t+g+\tau}^{d}}\right]^{-\vartheta}\right. \\
& \left.-\frac{W_{t+\tau+g}}{P_{t+\tau+g}^{d}} \frac{f^{-1}\left[\widehat{Y}_{t+\tau+g}^{d}\left(\frac{\widetilde{P}_{t+g}^{d}\left(\frac{P_{t+\tau+g-1}^{d}}{P_{t+g-1}^{d}}\right)^{\zeta}}{P_{t+g+\tau}^{d}}\right)^{-\vartheta}\right]}{A_{t+\tau+g}}\right\},
\end{aligned}
$$

where $\widetilde{\lambda}_{t}^{d}, \widetilde{P}_{t+g}^{d}$ and $\zeta$ denote, respectively, the marginal utility of domestic goods, the new price chosen in period $t$ for period $t+g$ and the degree of indexation to the previous period inflation rate ${ }^{14}$. Following Svensson (2000), I set $\delta=1$ to ensure the natural-rate hypothesis. Finally, assuming that the purchasing power parity holds in the long run, the log-linearized version of the Phillips curve for the domestic sector turns out to be

$$
\pi_{t+2}^{d}=\frac{1}{1+\zeta}\left[\zeta \pi_{t+1}^{d}+\pi_{t+3 \mid t}^{d}+\frac{(1-\alpha)^{2}}{\alpha(1+\omega \vartheta)}\left(\omega y_{t+2 \mid t}^{d}+\mu q_{t+2 \mid t}\right)\right]+\varepsilon_{t+2}
$$

where $\omega$ is the output elasticity of the marginal input requirement function and $\varepsilon_{t+2}$ is a zero-mean i.i.d. cost-push shock.

In line with the central banks' experience of an approximate two-period lag required to affect domestic inflation, I derive (21) assuming that pricing decisions are predetermined two periods in advance, i.e. $g=2$. Equation $(21)$ is equal to the Svensson (2000) aggregate supply, except (i) for the inertia in the inflation dynamics, which is here also based on the indexation to past inflation and (ii) for the characterization of import goods, which in this model are generally different from foreign

\footnotetext{
${ }^{14}$ Recalling that consumption decisions are predetermined one period in advance, the marginal utility of domestic goods $\widetilde{\lambda}_{t}^{d}$ is obtained by the following first-order condition with respect to $C_{t+1}^{d}$

$$
E_{t} U_{d}\left(C_{t+1}^{d}, C_{t+1}^{i}\right)=E_{t}\left[\lambda_{t+1} P_{t+1}^{d}\right] \equiv E_{t} \widetilde{\lambda}_{t+1}^{d},
$$
}

where $\lambda_{t}$ is the marginal utility of nominal income in period $t$. 
$\operatorname{goods}^{15}$.

According to (21), inflation is a predetermined variable based, on the one hand, on expectations of future inflation, demand and input price relying on the information set available two periods ago. On the other hand, it is based on previous value of inflation. It is worth noting that the relevance of the assumptions of (i) predetermined pricing decision and (ii) indexation to the previous period inflation is in improving the empirical fit. Indeed, as shown by Woodford (2003), these assumptions eliminate two counterfactual predictions of the basic Calvo model, i.e. the immediate and sharp reaction of inflation to monetary policy shocks.

Equation (21) shows that beyond the aggregate demand and the inflation expectations channels, monetary policy affects domestic inflation via the impact of the nominal exchange rate on the real price of the input, which turns out to be equal to $\mu q_{t}{ }^{16}$. This is the second of the three exchange rate channels embedded in this model. The strength of this channel depends on nominal rigidities, imperfect competition and the (degree of) convexity of the input required function captured, respectively, by $\alpha$, $\vartheta$ and $\omega$. Also, it depends on the relevance of the import goods in the production of the domestic goods, which is captured by $\mu$, and, indirectly, on the characteristics of the pass-through ${ }^{17}$.

\subsubsection{Import sector}

Similarly to the domestic sector, variety $j$ of the import goods, $Y_{t}^{i}(j)$, is produced by the representative consumer/producer $j$ with a composite input whose price is $F_{t}$. Since the input requirement function is $\frac{1}{A_{t}^{i}} f^{-1}\left[Y_{t}^{i}(j)\right]$, the variable cost of producing the quantity $Y_{t}^{i}(j)$ is $F_{t} \frac{1}{A_{t}^{i}} f^{-1}\left[Y_{t}^{i}(j)\right]$. Furthermore, since there is a Dixit-Stiglitz aggregate of import goods with elasticity of substitution $\vartheta>1$, the demand for variety $j$ is

$$
Y_{t}^{i}(j)=\widehat{Y}_{t}^{i}\left(\frac{P_{t}^{i}(j)}{P_{t}^{i}}\right)^{-\vartheta}
$$

where $P_{t}^{i}(j)$ is the nominal price for variety $j$, and $P_{t}^{i}$ is the Dixit-Stiglitz price index for import goods. Finally, considering that the input is a convex combination of the aggregate of domestic goods and of the foreign good, with price $P_{t}^{*} S_{t}$, where $P_{t}^{*}$ is the price in foreign currency of the foreign good, it follows that $F_{t} \equiv \mu^{i} P_{t}^{d}+\left(1-\mu^{i}\right) P_{t}^{*} S_{t}$.

Now relaxing the assumption that pricing decisions are predetermined $g$ periods

\footnotetext{
${ }^{15}$ Here import and foreign goods coincide in the special case of complete pass-through, which is described below.

${ }^{16}$ Indeed, log-linearizing the real price of the composite input $\frac{W_{t}}{P_{t}^{d}}$ around the steady state yields $\mu q_{t}$.

${ }^{17}$ As it will be shown below, the terms of trade $q_{t}$ depend on the price level in the import sector, which in turn depends on the pass-through.
} 
in advance, the problem of the consumer/producer $j$ is

$$
\left.\begin{array}{c}
\max _{\widetilde{P}_{t}^{i}} E_{t} \sum_{\tau=0}^{\infty} \alpha^{\tau} \delta^{\tau} \widetilde{\lambda}_{t+\tau}^{i}\left\{\frac{\widetilde{P}_{t}^{i}\left(\frac{P_{t+\tau-1}^{i}}{P_{t-1}^{i}}\right)^{\zeta}}{P_{t+\tau}^{i}} \widehat{Y}_{t+\tau}^{i}\left(\frac{\widetilde{P}_{t}^{i}\left(\frac{P_{t+\tau-1}^{i}}{P_{t-1}^{i}}\right)^{\zeta}}{P_{t+\tau}^{i}}\right)^{-\vartheta}\right. \\
\left.-\frac{F_{t+\tau}}{P_{t+\tau}^{i}} \frac{f^{-1}\left[\widehat{Y}_{t+\tau}^{i}\left(\frac{\widetilde{P}_{t}^{i}\left(\frac{P_{t+\tau-1}^{i}}{P_{t-1}^{i}}\right)^{\zeta}}{P_{t+\tau}^{i}}\right)^{-\vartheta}\right]}{A_{t+\tau}}\right\}
\end{array}\right\}
$$

where $\widetilde{P}_{t}^{i}, \widetilde{\lambda}_{t}^{i}, \alpha^{i}$ have the same meaning of their analogous variables in the domestic sector. Here, the assumption of $g=0$ is motivated by the fact that the import sector acts as a retailer sector for the foreign goods and, in practice, retailers do not set their price before they take effect as much as producers do.

Then, assuming $\delta=1$ and that the purchasing power parity holds in the long run, the log-linearized version of the Phillips curve in the import sector is given by

$$
\pi_{t}^{i}=\frac{1}{1+\zeta}\left[\zeta \pi_{t-1}^{i}+\pi_{t+1 \mid t}^{i}+\frac{\left(1-\alpha^{i}\right)^{2}}{\alpha^{i}(1+\omega \vartheta)}\left(\omega y_{t}^{i}+q_{t}^{i}\right)\right],
$$

where $q_{t}^{i}$ denotes (the log deviation of) the price of the composite input in the import sector expressed in terms of the import goods price, $p_{t}^{i}$, and is defined as

$$
q_{t}^{i} \equiv\left(1-\mu^{i}\right)\left(s_{t}+p_{t}^{*}\right)+\mu^{i} p_{t}^{d}-p_{t}^{i},
$$

where $p_{t}^{*}$ is the $(\log )$ foreign price level. It is worth noting that the introduction of the variable $q_{t}^{i}$ is a convenient way to obtain an aggregate supply relation in terms of stationary variables.

Equation (22) is derived in a similar way to (21). Here, however, pricing decisions are no longer assumed to be predetermined. As a result, $\pi_{t}^{i}$ is a forward looking variable and we have a direct inflation expectation channel working via $\pi_{t+1 \mid t}^{i}$ and a third exchange rate channel working via $q^{i}$, the $\mathrm{DERC}^{18}$. To describe incomplete passthrough, it is worth recalling that production in the import sector uses foreign goods and the goods produced in the domestic sector. The need of distribution services motivates the presence of the goods produced in the domestic sector. Specifically, it is assumed that to bring one unit of the foreign good to domestic consumers requires some units of a basket of differentiated domestic goods. Consequently, by introducing a wedge between the price of the foreign goods paid by the domestic consumers and by

\footnotetext{
${ }^{18} \mathrm{It}$ is interesting to note that part of the direct expectation channel adds to the DERC. Indeed, equation (22) can be solved forward to obtain

$$
\pi_{t}^{i}=\zeta \pi_{t-1}^{i}+\frac{\left(1-\alpha^{i}\right)^{2}}{\alpha^{i}(1+\omega \vartheta)} \sum_{\tau=0}^{\infty}\left(\omega y_{t+\tau \mid t}^{i}+q_{t+\tau \mid t}^{i}\right)
$$

which shows that the DERC works not only via $q_{t}^{i}$ but also via all the sequence of $q_{t}^{i}$, i.e. $\left\{q_{t+\tau \mid t}^{i}\right\}_{\tau=0}^{\infty}$.
} 
the retailers, this assumption models the degree of completeness of the pass-through. In particular, it establishes an inverse relation between the completeness of the passthrough and the need of distribution services captured by the coefficient $\mu^{i}$.

A notable feature of this Phillips curve is that the stickiness in the price adjustment determines the speed of the pass-through. When $\alpha^{i}=0$, all the firms in the import sector set in any period their price equal to a mark-up over the marginal cost. Thus a shock to the exchange rate or the foreign price feeds immediately to the price of the import goods. In addition, if we assume also no local inputs, $\left(\mu^{i}=0\right)$, we obtain the benchmark case of perfect (i.e. complete and immediate) pass-through where the DERC reaches its greatest efficiency.

\subsubsection{CPI inflation}

Considering the log-linearized version of the CPI price equation (3), CPI-inflation, $\pi_{t}^{c}$, is given by

$$
\pi_{t}^{c}=(1-w) \pi_{t}^{d}+w \pi_{t}^{i}
$$

Since $\pi_{t}^{d}$ is predetermined, at time $t$ monetary policy can affect $\pi_{t}^{c}$ only with $\pi_{t}^{i}$. Specifically, since $y_{t}^{i}$ is predetermined as well, monetary policy affects $\pi_{t}^{c}$ by steering the nominal exchange rate which is a forward looking variable given the uncovered interest parity (always fulfilled) and the purchasing power parity (fulfilled only in the long run). Then, monetary policy affects $\pi_{t}^{i}$ according to the Phillips curve (22) via the impact of the exchange rate on the real price of the input in the import sector illustrated by equation (23) and via $\pi_{t+1 \mid t}^{i}$. This indicates the role of the DERC and expectations in allowing monetary policy to have an impact on CPI inflation in the short run.

\subsection{Uncovered interest parity in terms of $q^{i}$, transmission channels and lags}

In order to eliminate the non-stationary nominal exchange rate, it is convenient to express the UIRP in terms of $q_{t}^{i}$ obtaining

$$
q_{t+1 \mid t}^{i}-q_{t}^{i}=\left(1-\mu^{i}\right) r_{t}-\left(1-\mu^{i}\right)\left(i_{t}^{*}-\pi_{t+1 \mid t}^{*}\right)-\left(\pi_{t+1 \mid t}^{i}-\pi_{t+1 \mid t}^{d}\right),
$$

where $r_{t}$ is the short term real interest rate defined as $r_{t} \equiv i_{t}-\pi_{t+1 \mid t}^{d}$.

Summing up, almost all channels need some time to convey the monetary policy to inflation. With the aggregate demand channel there is a (one-period) lag to transmit the stimulus to CPI inflation via the output-gap in the import sector, and a (twoperiod) lag to affect domestic inflation via the expected output-gap in the domestic sector ${ }^{19}$. With both the inflation expectations channel and with the channel that transmits the impact of the exchange rate to the price of the input in the domestic sector, i.e. $\mu q_{t+2 \mid t}$ in equation (21), there is a (two-period) lag to affect domestic inflation due to predetermined price setting behavior. The only channels for which there is no lag are the direct inflation expectation channel and the DERC. For the latter, the real interest parity condition (25) conveys the monetary impulse to the real price of the composite input in the import sector, $q_{t}^{i}$, which, in turn, directly hits import sector inflation.

\footnotetext{
${ }^{19}$ It is a common assumption in the literature that the aggregate demand channel affects inflation with a two-period lag.
} 


\subsection{The public sector}

The behavior of the central bank consists of minimizing the following loss function

$$
E_{t} \sum_{\tau=0}^{\infty} \beta^{\tau}\left[\mu^{c} \pi_{t+\tau}^{c 2}+\mu^{d} \pi_{t+\tau}^{d 2}+\lambda y_{t+\tau}^{d 2}+\nu\left(i_{t+\tau}-i_{t+\tau-1}\right)^{2}\right],
$$

where $\mu^{d}, \mu^{i}, \lambda$ and $\nu$ are weights that express the preferences of the central bank for the CPI and domestic inflation targets, the output stabilization target and the instrument smoothing target respectively.

\subsection{The rest of the world}

I assume stationary univariate $\mathrm{AR}(1)$ processes for the exogenous variables foreign inflation and income

$$
\begin{aligned}
\pi_{t+1}^{*} & =\gamma_{\pi}^{*} \pi_{t}^{*}+\varepsilon_{t+1}^{*}, \\
y_{t+1}^{*} & =\gamma_{y}^{*} y_{t}^{*}+\eta_{t+1}^{*},
\end{aligned}
$$

where the coefficients are non-negative and less than unity and the shocks are white noises. Finally, the foreign sector sets the monetary policy according to the following Taylor rule

$$
i_{t}^{*}=f_{\pi}^{*} \pi_{t}^{*}+f_{y}^{*} y_{t}^{*}+\xi_{i t}^{*},
$$

where the coefficients are positive and $\xi_{i t}^{*}$ is a white noise.

\subsection{Calibration}

The choice of the structural parameters mostly follows Svensson (2000). See the Appendix for the full set of parameters.

\section{Optimal monetary policy}

To recap, the model consists of the maximization of the central bank, firms and households preferences and their optimal behaviors are described by structural relations, namely the reaction function for the central bank, the aggregate supplies for the firms and the aggregate demands for the households.

In this general equilibrium model, the (column) vectors of predetermined ${ }^{20}$, forwardlooking variables and innovations to the predetermined variables are, respectively,

$$
\begin{aligned}
& X_{t}=\left(\pi_{t}^{d}, \pi_{t+1 \mid t}^{d}, \pi_{t-1}^{i}, \pi_{t}^{*}, y_{t}^{d}, y_{t}^{i}, y_{t}^{*}, i_{t}^{*}, y_{t}^{d, n}, y_{t}^{i, n}, i_{t-1} q_{t-1}, q_{t-1}^{i}\right)^{\prime}, \\
& x_{t}=\left(\pi_{t}^{i}, q_{t}^{i}, \rho_{t}, \pi_{t+2 \mid t}^{d}\right)^{\prime} . \\
& \nu_{t}=\left(\varepsilon_{t}, \zeta \varepsilon_{t}, 0, \varepsilon_{t}^{*}, \eta_{t}^{d}-\eta_{t}^{d, n}, \eta_{t}^{i}-\eta_{t}^{i, n}, \eta_{t}^{*}, f_{\pi}^{*} \varepsilon_{t}^{*}+f_{y}^{*} \eta_{t}^{*}+\xi_{i, t}^{*}, \eta_{t}^{d, n}, \eta_{t}^{i, n}, 0,0,0\right)^{\prime} .
\end{aligned}
$$

\footnotetext{
${ }^{20} \mathrm{It}$ is worthwhile pointing out that $\pi_{t+1 \mid t}^{d}$ is a predetermined variable. This is apparent if we consider the domestic sector Phillips curve and take the expectation at time $t+1$ because $\varepsilon_{t+2 \mid t+1}=0$ and $\pi_{t+2 \mid t+1}^{d}$ is a function of predetermined variables.
} 
In this model the rational expectations equilibrium is the set of plans

$$
\left\{i_{t+\tau \mid t}, \pi_{t+\tau \mid t}^{d}, \pi_{t+\tau \mid t}^{i}, y_{t+\tau \mid t}^{d}, y_{t+\tau \mid t}^{i}, q_{t+\tau \mid t}, q_{t+\tau \mid t}^{i}\right\}_{\tau=0}^{\infty}
$$

such that, for any given vector of the shocks and set of plans for the exogenous variables, (i) the central bank maximizes its preferences, (ii) the households maximize their utilities and (iii) the firms maximize their profits. Since each agent takes the (optimal) behavior of the other agents as given in his decision process, these plans are also a Nash equilibrium.

Intuitively, the central bank chooses the instrument-rate plan $\left\{i_{t+\tau \mid t}\right\}_{\tau=0}^{\infty}$ that, given the lags in transmission channels, determines expectations of future inflation and output with the smallest variability and in line with their targets at a certain time horizon. Thus, the more forward looking the private sector behavior, the more monetary policy consists of the management of the expectations.

Concerning the optimal monetary policy, the model presents a time-invariant reaction function which is the first order condition obtained by the intertemporal optimization of the central bank preferences. This function is linear in the vector of the predetermined variables and since the model is linear-quadratic and uncertainty enters additively, certainty equivalence holds and it does not depend on the covariance matrix of the shocks. To find this reaction function I used the dynamic programming technique of the linear stochastic regulator with rational expectations and forwardlooking variables ${ }^{21}$.

\subsection{Domestic and CPI inflation-targeting}

Table 1 and 2 report the coefficients of the reaction functions for the cases of strict and flexible domestic and CPI inflation-targeting under various assumptions on the types and degree of pass-through ${ }^{22}$.

Table 1. Domestic inflation-targeting, reaction-function coefficients

\begin{tabular}{|c|l|l|l|l|l|l|l|l|l|l|l|l|l|}
\hline Strict dom. & $\pi_{t}^{d}$ & $\pi_{t+1 \mid t}^{d}$ & $\pi_{t-1}^{i}$ & $\pi_{t}^{*}$ & $y_{t}^{d}$ & $y_{t}^{i}$ & $y_{t}^{*}$ & $i_{t}^{*}$ & $y_{t}^{d, n}$ & $y_{t}^{i, n}$ & $i_{t-1}$ & $q_{t-1}$ & $q_{t-1}^{i}$ \\
\hline Perf., $\mu^{i}=0, \alpha^{i}=0.05$ & 0.00 & 1.49 & 0.00 & 0.08 & 0.08 & -0.00 & 0.07 & -0.02 & -0.07 & -0.02 & 0.52 & 0.00 & 0.00 \\
\hline Inc., $\mu^{i}=0.5, \alpha^{i}=0.05$ & 0.00 & 1.54 & 0.00 & 0.03 & 0.09 & -0.01 & 0.04 & -0.01 & -0.08 & -0.01 & 0.51 & 0.00 & 0.00 \\
\hline Del., $\mu^{i}=0, \alpha^{i}=0.5$ & -0.01 & 1.49 & 0.03 & 0.08 & 0.08 & 0.02 & 0.09 & 0.01 & -0.08 & 0.00 & 0.48 & 0.01 & 0.00 \\
\hline Del., Inc., $\mu^{i}=0.5, \alpha^{i}=0.5$ & 0.00 & 1.53 & 0.02 & 0.03 & 0.09 & 0.01 & 0.05 & 0.00 & -0.09 & 0.00 & 0.50 & 0.00 & 0.00 \\
\hline \hline Flexible dom. & $\pi_{t}^{d}$ & $\pi_{t+1 \mid t}^{d}$ & $\pi_{t-1}^{i}$ & $\pi_{t}^{*}$ & $y_{t}^{d}$ & $y_{t}^{i}$ & $y_{t}^{*}$ & $i_{t}^{*}$ & $y_{t}^{d, n}$ & $y_{t}^{i, n}$ & $i_{t-1}$ & $q_{t-1}$ & $q_{t-1}^{i}$ \\
\hline Perf., $\mu^{i}=0, \alpha^{i}=0.05$ & 0.03 & 0.74 & 0.00 & 0.28 & 0.68 & 0.02 & 0.18 & -0.06 & -0.05 & -0.02 & 0.37 & -0.03 & 0.00 \\
\hline Inc., $\mu^{i}=0.5, \alpha^{i}=0.05$ & 0.02 & 0.76 & 0.00 & 0.08 & 0.71 & -0.01 & 0.07 & -0.03 & -0.09 & -0.03 & 0.38 & -0.02 & 0.00 \\
\hline Del., $\mu^{i}=0, \alpha^{i}=0.5$ & -0.02 & 0.74 & 0.06 & 0.10 & 0.70 & 0.03 & 0.12 & 0.02 & -0.11 & -0.00 & 0.36 & 0.02 & 0.00 \\
\hline Del., Inc., $\mu^{i}=0.5, \alpha^{i}=0.5$ & 0.01 & 0.75 & 0.03 & 0.06 & 0.71 & 0.02 & 0.07 & 0.00 & -0.11 & -0.01 & 0.37 & -0.01 & 0.00 \\
\hline
\end{tabular}

\footnotetext{
${ }^{21}$ In particular, since this optimization problem does not have a closed form solution, I used the Oudiz and Sachs (1985) algorithm, which is further discussed in Backus Driffil (1986), Curie and Levine (1993) and Soderlind (1999). The optimization problem is reported in Appendix B.

${ }^{22}$ For strict and flexible domestic inflation-targeting, the weights in the loss function are $\mu^{c}=$ $0, \mu^{d}=1, \lambda=0, \nu=0.01$, and $\mu^{c}=0, \mu^{d}=1, \lambda=0.5, \nu=0.01$, respectively. For strict and flexible $C P I$ inflation-targeting, the weights are $\mu^{c}=1, \mu^{d}=0, \lambda=0, \nu=0.01$, and $\mu^{c}=1, \mu^{d}=$ $0, \lambda=0.5, \nu=0.01$, respectively. The choice of the interest smoothing parameter $\nu$ balances two contrasting goals: To avoid a completely unrealistic monetary policy, which may occur when values of $\nu$ are too small and, on the other hand, to avoid an inefficient monetary policy as to the stabilization of CPI inflation, which instead occurs when $\nu$ is not sufficiently small.
} 
First of all, Table 1 shows that the optimal monetary policy is very simple: only the coefficients for expected domestic inflation $\pi_{t+1 \mid t}^{d}$, the lagged interest rate $i_{t-1}$ and, in the flexible case, the output-gap in the domestic sector $y_{t}^{d}$ and foreign variables $\pi_{t}^{*}$ and $y_{t}^{*}$ are sizeable, with the coefficient for $i_{t-1}$ different from zero because of interest rate smoothing.

Second, domestic inflation-targeting policies, in particular strict inflation-targeting, do not depend significantly on the pass-through. Indeed, changes in the type and degree of pass-through have a negligible impact on the coefficients.

Table 2. CPI-inflation-targeting, reaction-function coefficients

\begin{tabular}{|c|c|c|c|l|l|l|l|l|l|l|l|l|l|}
\hline Strict CPI & $\pi_{t}^{d}$ & $\pi_{t+1 \mid t}^{d}$ & $\pi_{t-1}^{i}$ & $\pi_{t}^{*}$ & $y_{t}^{d}$ & $y_{t}^{i}$ & $y_{t}^{*}$ & $i_{t}^{*}$ & $y_{t}^{d, n}$ & $y_{t}^{i, n}$ & $i_{t-1}$ & $q_{t-1}$ & $q_{t-1}^{i}$ \\
\hline Per., $\mu^{i}=0, \alpha^{i}=0.05$ & 0.46 & -3.27 & 0.07 & -0.01 & 0.00 & 0.55 & 0.54 & 0.97 & -0.01 & 0.22 & 0.00 & 0.02 & 0.00 \\
\hline Inc., $\mu^{i}=0.5, \alpha^{i}=0.05$ & 2.20 & -4.24 & 0.11 & 0.47 & -0.01 & 1.01 & 0.76 & 0.77 & 0.05 & 0.26 & 0.07 & -0.43 & 0.00 \\
\hline Del.., $\mu^{i}=0, \alpha^{i}=0.5$ & 2.65 & 0.25 & 0.40 & 0.44 & -0.02 & 0.15 & 0.35 & 0.15 & 0.15 & 0.00 & 0.43 & -0.26 & 0.00 \\
\hline Del., Inc., $\mu^{i}=0.5, \alpha^{i}=0.5$ & 2.10 & 1.09 & 0.28 & 0.30 & 0.00 & 0.13 & 0.22 & 0.05 & 0.11 & -0.04 & 0.52 & -0.32 & 0.00 \\
\hline Flexible CPI & $\pi_{t}^{d}$ & $\pi_{t+1 \mid t}^{d}$ & $\pi_{t-1}^{i}$ & $\pi_{t}^{*}$ & $y_{t}^{d}$ & $y_{t}^{i}$ & $y_{t}^{*}$ & $i_{t}^{*}$ & $y_{t}^{d, n}$ & $y_{t}^{i, n}$ & $i_{t-1}$ & $q_{t-1}$ & $q_{t-1}^{i}$ \\
\hline Per., $\mu^{i}=0, \alpha^{i}=0.05$ & 1.09 & -1.62 & 0.06 & 0.33 & 0.08 & 0.53 & 0.67 & 0.89 & 0.22 & 0.15 & 0.03 & -0.18 & 0.00 \\
\hline Inc., $\mu^{i}=0.5, \alpha^{i}=0.05$ & 2.02 & -2.49 & 0.09 & 0.47 & 0.30 & 0.79 & 0.66 & 0.62 & 0.11 & 0.15 & 0.12 & -0.42 & 0.00 \\
\hline Del.., $\mu^{i}=0, \alpha^{i}=0.5$ & 1.36 & -0.93 & 0.27 & 0.11 & 0.62 & 0.08 & 0.17 & 0.10 & -0.10 & 0.02 & 0.33 & 0.02 & 0.00 \\
\hline Del., Inc., $\mu^{i}=0.5, \alpha^{i}=0.5$ & 0.88 & -0.28 & 0.16 & 0.08 & 0.69 & 0.05 & 0.10 & 0.03 & -0.10 & -0.00 & 0.36 & -0.03 & 0.00 \\
\hline
\end{tabular}

Third, in contrast with the domestic inflation-targeting case, Table 2 shows that with CPI inflation-targeting the reaction function is sophisticated. This could be a disadvantage in that it could lead, in practice, to implementation problems. Furthermore, with CPI inflation-targeting, the pass-through affects the optimal monetary policy. Here, changes in sign and size of the coefficients stand out and show that with respect to the benchmark case of perfect pass-through, incomplete and delayed pass-through tend to have opposite effects on the monetary policy. In particular, incomplete pass-through leads to a more aggressive monetary policy while delayed pass-through leads to a less aggressive one. This result will also show up below in the Impulse Response Functions (IRFs). The intuition is that delayed pass-through reduces the efficiency of the DERC much more than incomplete pass-through ${ }^{23}$. Thus, the stabilization of CPI inflation requires a monetary policy which is more aggressive with delayed pass-through than with incomplete pass-through. Yet, a too aggressive monetary policy is not feasible because it generates more volatility in the interest rate and in the output-gap which increase the loss of the central bank ${ }^{24}$. As a result, with delayed pass-through, the optimal transmission mechanism uses the DERC channel less and monetary policy tends to give up the stabilization of $\pi_{t}^{c}$.

\footnotetext{
${ }^{23}$ This is apparent in (22) and (23) which show that delayed and incomplete pass-through affect $\pi_{t}^{i}$ in a non linear and linear way respectively.

${ }^{24}$ Further results available on request show that reducing the concern of the central bank on the interest rate smoothing and the stabilization of the output gap (in the flexible case) determines a monetary policy that with delayed pass-through is more aggressive than with incomplete passthrough.
} 


\section{$3.2 \quad$ Impulse responses}

In Figures (3-10) the impulse responses for domestic and CPI inflation-targeting under different assumptions on the pass-through are reported. They are generated assuming that the economy is in steady state and then is hit by a certain shock whose value is set equal to 1 .

In each figure, the first, second, third and fourth column refer, respectively, to the cases of perfect, incomplete, delayed and both incomplete and delayed passthrough. The shocks considered are a cost-push shock (Figures 3-6) and a foreign inflation shock (Figures 7-10). For sake of simplicity but without loss of generality, the description of the impulse response functions skips the intermediate step from the change of the instrument to the nominal exchange rate. In this way I focus directly on the impact of the monetary policy on the variable $q_{t}^{i}$, which is central in the use of the DERC. Yet, for sake of completeness I report the behavior of the nominal exchange rate which can always be explained by purchasing power parity (satisfied in the long run) and the uncovered interest parity provided by equation (5).

\subsubsection{Strict domestic inflation-targeting, IRF to a cost-push shock}

In Figure 3, optimal monetary policy works mainly via the aggregate demand channel and the two exchange rate channels other than the DERC.

Monetary policy consists of an initial increase of the nominal interest rate which is gradually taken back to zero (sixth row). Then, the real interest rate rises (seventh row) provoking a fall of the output-gap in the domestic sector (fourth row); this is the aggregate demand channel.

In order to contribute to the stabilization of $\pi^{d}$, the terms of trade, $q$, decreases. As a result, some demand switches from domestic to import goods (first exchange rate channel that adds to the aggregate demand channel) while the real price of the input in the domestic sector falls (second exchange rate channel that works via the production costs in the domestic sector).

Since in the import sector the switching demand effect tends to outstrip the effect of the increase in the real interest rate, $y^{i}$ slightly rises initially (fifth row). Now, a decrease in $q$ occurs if and only if $\pi^{d}$ is larger than $\pi^{i}$. Thus, to curb the increase of inflation in the import sector caused by $y^{i}, q^{i}$ has to decrease.

With incomplete pass-through (second column), the cost-push shock propagates to $q^{i}$ via equation (23) and the monetary policy lets that $q^{i}$ increase via the interest parity in terms of $q^{i}$. Consequently, to avoid that $\pi^{i}$ increase too much, $y^{i}$ has to fall (fifth row). This happens because now the aggregate demand effect outstrips the switching demand effect, and this is consistent with a path of $q$ which is less negative than before.

With delayed pass-through (third column), a change in $q^{i}$ and $y^{i}$ have a smaller impact on $\pi^{i}$. Now only half of the firms in the import sector can update the price optimally so that the elasticity of inflation to the real price of the input and to the output-gap in the import sector is much smaller ${ }^{25}$. Thus, monetary policy provokes a smaller increase in the import sector inflation, which in turn determines a larger decrease of the terms of trade. As a result, there are a stronger switching demand effect and fall in the price of the domestic sector input, which explain why monetary

\footnotetext{
${ }^{25}$ Note that in the case of immediate pass-through this elasticity tends to infinity so that an infinitesimal change of $q_{t}^{i}$ or $y_{t}^{i}$ is sufficient to increase $\pi_{t}^{i}$.
} 
policy can be slightly more moderate. It is worth noting here that delayed passthrough, by reducing the efficiency of the DERC, tends to improve the efficiency of the overall transmission mechanism, in particular of the other two exchange rate channels. Indeed, allowing this channel to absorb some of the monetary policy shock results in a smaller increase in the import sector inflation, which leads to a larger decrease of the terms of trade.

\subsubsection{Flexible domestic inflation-targeting, IRF to cost-push shock}

In the flexible domestic inflation-targeting cases (Figure 4), monetary policy is similar to, but more moderate than, the strict cases. Here the output-gap in the domestic sector is almost completely stabilized at the cost of a slightly longer period to stabilize domestic inflation.

\subsubsection{Strict CPI inflation-targeting, IRF to cost-push shock}

In Figure 5, with perfect pass-through (first column), optimal monetary policy manages to stabilize CPI inflation (first row) after a cost push shock. In the first two periods this shock can be absorbed only via the DERC and the direct expectation channel because domestic inflation is predetermined. As a result, to let inflation in the import sector offset the shock, monetary policy cuts the interest rate in $t$, increases it sharply in $t+1$ and takes it to zero in the subsequent periods. Such a policy allows $q^{i}$ to be sufficiently negative in the initial periods so that it outweights the positive impact of $y^{i}$ on the path of $\pi^{i}$. As to the rest of the economy, the sizable decrease of the terms of trade (ninth row) determines a strong switching demand effect portrayed respectively by the fall and rise of the output-gap in the domestic and import sector (fourth and fifth row).

When the pass-through is incomplete (second column), the ability to fully stabilize CPI inflation tends to decrease. Now the price of the input in the import sector depends also on local factors and, consequently, the DERC is less efficient. Thus, a more aggressive monetary policy is required which, however, is bounded by the interest smoothing constraint.

When the pass-through is delayed (third column) only half of the firms in the import sector is allowed to update optimally the current price of the import. This results in a more relevant reduction of the DERC efficiency because now optimal monetary policy can reduce the current cost of production only for half of the firms. Thus, an even more aggressive and volatile monetary policy is required to stabilize CPI, which is not feasible due to the interest smoothing constraint. As a result, CPI inflation stabilization is reduced even more.

Finally, when the pass-through is incomplete and delayed (fourth row), these two sources of inefficiency of the DERC add up resulting in a largest variability of CPI inflation.

\subsubsection{Flexible CPI inflation-targeting, IRF to cost-push shock}

With flexible CPI inflation-targeting, Figure 6, an intense use of the DERC to stabilize CPI inflation is no longer feasible due to the deep and long fall that it would generate in the output-gap. Yet, comparing this case with the flexible domestic inflationtargeting case reported in Figure 4, shows that in the initial periods, in the former case, inflation in the import sector is kept low in order to stabilize CPI inflation. 
Thus, the DERC is still actively used in flexible CPI inflation-targeting, and the third row in Figure 6 reveals that its role in the transmission mechanism tends to decrease moving from perfect to the imperfect pass-through cases.

\subsubsection{Strict domestic inflation-targeting, foreign inflation shock}

It is noteworthy that in this model shocks in foreign inflation or income tend to have a similar qualitative impact on the domestic economy. This is due to the fact that to a large extent they share the same transmission mechanism because the foreign economy is assumed to set the monetary policy according to the Taylor rule. Indeed, a change in either foreign inflation or income has the same qualitative impact on the foreign interest rate, which in turn affects the domestic interest rate through the uncovered parity condition. In addition, foreign inflation and income have a similar impact on the demand of home goods via the aggregate demand channel.

For example, let us consider a foreign inflation shock. Now domestic inflation is unaffected in the first two periods and from the third period on it depends on the sequence of expectations of the output-gap and of the terms of trade taken in $t^{26}$. The shock increases the price of the input in the import sector. When the pass-through is perfect (Figure 7, first column), all the firms in the import sector respond optimally to the shock in period $t$. Since demand is predetermined, the firms in the import sector can offset the shock completely by raising their price in period $t$ (third row). This determines an increase of the terms of trade (eight row), which on the one hand switches the demand from the import to the domestic sector and, on the other hand, tends to increase the production costs in the domestic sector. Therefore, to avoid an upward pressure on domestic inflation, the optimal monetary policy increases the nominal interest rate causing a slight fall of the output-gap in the domestic sector (fourth row).

When the pass-through is incomplete (second column), both foreign goods and local inputs are used in the import sector. Thus the impact of the foreign inflation shock on the production cost in the import sector decreases. As a result the optimal monetary policy and the response of the economy exhibit only a quantitative difference with the perfect pass-through case.

With delayed pass-through (third column), only half of the firms in the import sector can react optimally to the shock. This explains why inflation in the import sector and the terms of trade rise less (third and ninth row) and the real cost of production in the import sector rises more (eight row).

It is interesting to note that the type and degree of pass-through do not affect the ability of the central bank in stabilizing domestic inflation. However, imperfect passthrough tends to shield the economy from the shock in that it reduces the efficiency of the DERC in propagating the shock. This is more apparent in the case of delayed and incomplete pass-through, (fourth column), which is characterized by less variability of $\pi^{i}, \pi^{c}$ and $q$.

\subsubsection{Flexible domestic inflation-targeting, foreign inflation shock}

In Figure 8, with flexible domestic inflation-targeting, the objective of output-gap stabilization slightly constrains the stabilization of $\pi^{d}$. Furthermore, the monetary

\footnotetext{
${ }^{26}$ This can be shown by taking the expectation in $t$ of the domestic sector AS and solving it forward.
} 
policy and the response of the economy differ only quantitatively and to a minor extent with the ones with strict domestic inflation-targeting.

\subsubsection{Strict CPI inflation-targeting, foreign inflation shock}

In Figure 9, for the various cases of pass-through, the monetary policy and the response of the economy are similar: the shock exerts a pressure on inflation in the import sector and consequently on CPI inflation. The response of the monetary policy consists of a hike of the instrument $i_{t}$ (sixth row) which is then gradually taken back to zero. This policy lets the DERC initially absorb the shock. Then, the aggregate demand channel is available (because the output-gap is no longer predetermined) and it carries out the stabilization of $\pi^{i}$ in the subsequent periods by a fall in the outputgap in the import sector (fifth row). This restrictive monetary policy also determines a fall in the output-gap in the domestic sector (forth row) and it is via the positive path of $q$ (ninth row) that deflation in the domestic sector does not occur.

A common feature with the case of strict domestic inflation-targeting is that the type and degree of pass-through does not affect the ability of the central bank in stabilizing inflation. A difference is that moving from perfect to imperfect passthrough does not reduce the variability of $\pi^{c}, \pi^{i}$ and $q$.

\subsubsection{Flexible CPI inflation-targeting, foreign inflation shock}

As expected, now less variability in the output-gap is achieved at the cost of more variability in CPI inflation. The various cases reported in Figure 10 differ with the case of strict CPI inflation-targeting (Figure 9) for a minor use of both the DERC and the aggregate demand channel. These changes are reflected for the DERC in a larger inflation in the import sector (third row) and, for the demand channel, in a minor decline of the output-gap (fourth row). This result is obtained with a slightly different interest rate plan that results in a less tight monetary policy.

\section{Imperfect pass-through and volatility in economic ac- tivity}

This section focuses on the relation between the pass-through and the volatility in economic activity and analyzes how the central bank could use this relation to improve its stabilization task.

\subsection{Taylor curves}

Figure 1 and 2 below illustrate, respectively, the Taylor curves for various degrees of incompleteness and delay of the pass-through when the central bank is following CPI inflation-targeting. 


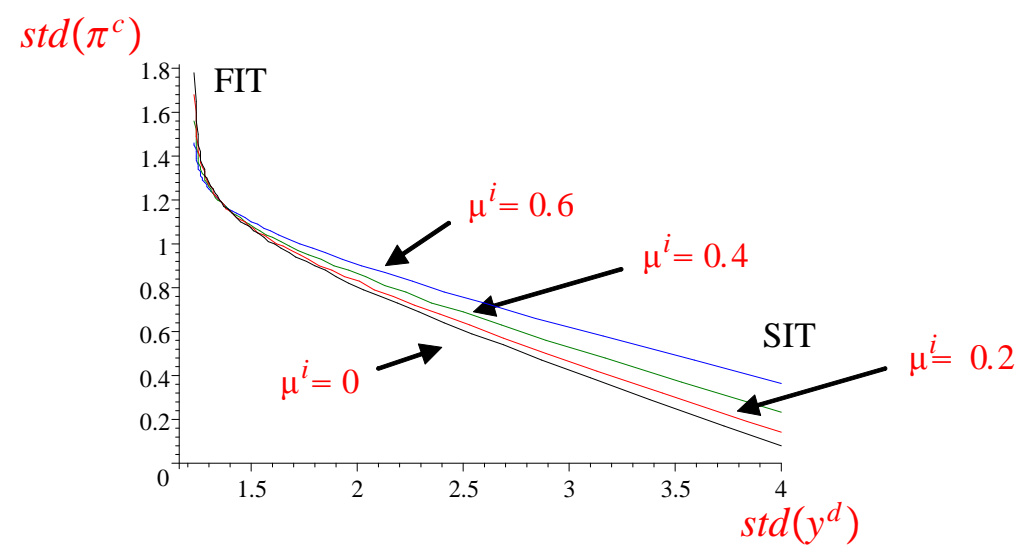

Figure 1. CPI inflation-targeting with incomplete and immediate PT, $\mu^{i} \in\{0,0.2,0.4,0.6\}, \alpha^{i}=0.05$.

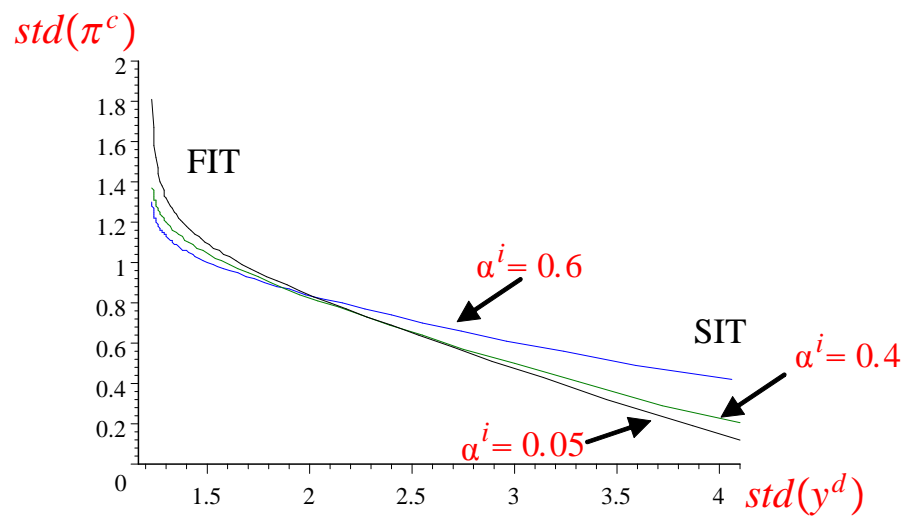

Figure 2. CPI inflation-targeting with delayed and complete PT, $\alpha^{i} \in\{0.05,0.4,0.6\}, \mu^{i}=0$.

These Taylor curves show that the trade-off between the variability of the outputgap and CPI inflation worsens when the pass-through is more incomplete and/or delayed. It is noteworthy that the impact of the pass-through tends to be stronger, the more the central bank cares about CPI-inflation stabilization (strict inflationtargeting, SIT) versus output-gap stabilization (flexible inflation-targeting, FIT). This is due to the lower efficiency of the DERC, which is important to stabilize CPI inflation in the short run.

The relation between the pass-through and the Taylor curves is even more interesting if one considers the relation between the inflation environment and the pass-through. With respect to the latter, there is a growing view in the literature for that moving to a lower inflation environment decreases the pass-through. This idea is consistent with the observation that a lower pass-through coupled with a more credible commitment to stabilize inflation has occurred in the last ten years. Theoretically, Taylor (2000) provided the first motivation for this relation showing how moving to a lower inflation environment reduces the pass-through by decreasing the expected persistence of cost changes. This relation is also supported empirically, for example, in Bailliu and Fujii (2004) $)^{27}$. Thus, if we assume following Taylor (2000)

\footnotetext{
${ }^{27}$ For other explanations and empirical evidence concerning the relation between the inflation environment and the pass-through see also Coudhry and Hakura (2001), Devereux and Yetman (2002) and Deverux, Engel, and Storgaard (2003).
} 
that a stable and lower inflation reduces the pass-through, to achieve a lower variability of CPI inflation could turn out to be more costly than expected in terms of output-gap variability. A case in point might be a central bank that decides to switch to inflation-targeting. Indeed, consider Figure 2 and suppose that due to a high initial inflation the pass-through tends to be immediate, for instance consider the Taylor curve with $\alpha^{i}=0.05$. Then suppose that the inflation variability is around 1 std and that, on the basis of this Taylor curve, the new inflation target monetary policy aims to achieve a variability of 0.4 std accepting a resulting output-gap variability of 3.2 std. Yet, the more CPI inflation variability falls, the worse is the trade-off so that it turns out to be impossible to attain the pair $(0.4,3.2)$. In fact, the pass-through is more delayed (say $\alpha^{i}=0.6$ ) and the $0.4 \mathrm{CPI}$ std target requires 4.1 std in the output-gap.

In summary, this analysis leads to two results. The first is that it is important to know the type and degree of the pass-through to assess the attainable output-gap-CPI inflation variabilities trade-offs. The second is that, combining this finding with the literature on the relation between the pass-through and the inflation environment, a chosen variability of CPI inflation could be achieved at a output-gap variability cost much higher than expected.

These results suggest an extension for further research in introducing endogenously the impact of the monetary policy on the pass-through. This could be done for instance via a Phillips curve that allows the degree of price stickiness to be determined endogenously as in Bakhshi et al. (2004). 


\subsection{Unconditional standard deviations, imperfect exchange rate pass- through and choice of the inflation target}

The following tables report the unconditional standard deviations for the main macrovariables in the model.

Table 3: Unconditional standard deviations

\begin{tabular}{|c|c|c|c|c|c|c|}
\hline Targeting case & $\pi_{t}^{c}$ & $\pi_{t}^{d}$ & $\mathbf{y}_{t}^{d}$ & $\mathbf{q}_{t}$ & $\mathbf{i}_{t}$ & $\mathbf{r}_{t}$ \\
\hline 1. Strict domestic inflation-targeting & & & & & & \\
\hline 1.a Perfect PT & 1.27 & 1.22 & 1.52 & 4.11 & 1.41 & 0.88 \\
\hline 1.b.Incomplete PT & 1.17 & 1.22 & 1.50 & 2.62 & 1.47 & 0.92 \\
\hline 1.c Delayed PT & 1.01 & 1.22 & 1.52 & 2.68 & 1.35 & 0.82 \\
\hline 1.d Incom. and del. PT & 1.04 & 1.22 & 1.49 & 2.08 & 1.43 & 0.89 \\
\hline 2. Flexible domestic inflation-targeting & & & & & & \\
\hline 2.a Perfect PT & 1.56 & 1.30 & 1.26 & 4.09 & 1.32 & 1.11 \\
\hline 2.b Incomplete PT & 1.38 & 1.29 & 1.26 & 2.61 & 1.35 & 1.15 \\
\hline 2.c Delayed PT & 1.21 & 1.29 & 1.27 & 2.42 & 1.30 & 1.13 \\
\hline 2.d Incom. and del. PT & 1.20 & 1.29 & 1.26 & 1.83 & 1.33 & 1.14 \\
\hline 3. Strict CPI inflation-targeting & & & & & & \\
\hline 3.a Perfect PT & 0.03 & 1.51 & 4.17 & 7.80 & 3.59 & 4.60 \\
\hline 3.b Incomplete PT & 0.17 & 1.51 & 4.70 & 7.22 & 5.08 & 5.98 \\
\hline 3.c Delayed PT & 0.46 & 1.36 & 3.04 & 5.61 & 4.37 & 4.35 \\
\hline 3.d Incom. and del. PT & 0.69 & 1.30 & 3.32 & 3.91 & 4.31 & 4.20 \\
\hline 4.a Perfect PT & & & & & & \\
\hline 4.b Incomplete PT & 0.94 & 1.23 & 1.72 & 3.13 & 2.02 & 2.10 \\
\hline 4.c Delayed PT & 1.05 & 1.22 & 1.59 & 2.36 & 2.06 & 1.99 \\
\hline 4.d Incom. and del. PT & 1.03 & 1.24 & 1.45 & 2.78 & 1.49 & 1.18 \\
\hline Flexible CPI inflation-targeting & 1.24 & 1.34 & 2.04 & 1.48 & 1.19 \\
\hline
\end{tabular}

First, Table 3 shows that the impact of the pass-through on the volatility of the economy is smaller with domestic than with CPI inflation-targeting. Indeed, with domestic inflation-targeting only the variability of $\pi^{c}$ and $q$ decreases significantly when the pass-through is incomplete and/or delayed. In particular, the variability of $y^{d}$ is not affected. In contrast, with CPI inflation-targeting, the pass-through also affects the variability of the other variables. Furthermore, with CPI inflationtargeting the variability in economic activity tends to rise. Yet, the concern for interest rate smoothing and the output-gap stabilization prevents it from increasing too much $^{28}$.

Second, imperfect pass-through tends to have opposite effects on the volatility of $\pi^{c}$ with the two inflation targets. Specifically, it decreases the volatility with domestic inflation-targeting while increases it with CPI inflation-targeting. Furthermore, with any inflation targets, imperfect pass-through reduces the variability of $q$. These results depend on two factors. The first is that imperfect pass-through reduces the efficiency of the DERC. Since CPI inflation stabilization relies significantly on this channel, less efficiency of the DERC requires a more aggressive monetary policy that, in turn, leads to an excessive variability of the other macro variables, in particular

\footnotetext{
${ }^{28}$ This explains why, with strict CPI, moving from the benchmark case to the incomplete passthrough case, the variability of $\pi^{c}, y$ and $i$ increase. Yet, moving from the benchmark case to delayed pass-through, the variability of $i$ rises less, of $\pi^{c}$ rises more and the one of $y$ falls.
} 
output. Thus, with imperfect pass-through and realistic monetary policy the central bank has to give up to some extent the stabilization of CPI inflation. This leads to less variability in import good inflation which, in turn, leads to less variability of the real exchange rate. The second factor is that a less efficient DERC tends to absorb foreign shocks that hit foreign inflation. Consequently, the variability of inflation in the import good is less resulting in less variability also of the terms of trade and CPI inflation.

Finally, focusing on the realistic case of flexible inflation-targeting and comparing domestic with CPI inflation-targeting, the latter case leads to a smaller variability of the inflation target but at the cost of introducing in the economy a larger variability in domestic output. Thus the choice of the target depends on to what extent the central bank accepts output volatility. A central bank that switches to inflationtargeting and has yet to acquire a solid reputation, may initially find it useful to use CPI inflation as the target. Indeed, it allows a better control of inflation in the short run and ensures less overall volatility of this variable. These are both important to build its reputation, a crucial ingredient to efficiently shape expectations. Yet, for a central bank that has already established its credibility, it seems better to choose domestic inflation as the target. Indeed, this target generates significantly less volatility in the output. Furthermore, it is worth noting that the advantage of the CPI target fades away the more the pass-through is incomplete and delayed. Indeed, the gap between the variability of $\pi^{d}$ and $\pi^{c}$ in the two cases shrinks. Also, CPI inflation-targeting leads in general to a larger variability in the interest rate and, with delayed pass-through, it also generates a larger volatility of the terms of trade $^{29}$. Finally, as shown in Table 2, CPI inflation-targeting necessitates a more sophisticated monetary policy than domestic inflation-targeting, leaving room for potential errors in its implementation. Consequently, this analysis supports domestic inflation-targeting with imperfect pass-through and shows the costs and benefits of CPI inflation-targeting with perfect pass-through. This finding is consistent with the previous analysis and relies on the efficiency of the DERC and its role in the transmission mechanism. Thus, depending on the relevance in practice of imperfect pass-through, this model adds a new dimension to question the general practice of inflation-targeting central banks that choose CPI inflation as the inflation measure to target.

\section{Conclusions}

In this paper I have analyzed the relation between the exchange rate pass-through and the optimal monetary policy for a small open-economy pursuing inflation-targeting. Earlier papers have studied this relation, yet none of them embeds a sophisticated transmission mechanism with stylized realistic lags, the inflation forecast targeting procedure and the analysis of both incomplete and delayed pass-through. These features are relevant because they allow characterizing better the monetary policies available to an inflation-targeting central bank and their implications in terms of the variability of the economy. Specifically, incorporating these features into a full-blown microfounded model, results in the following results.

\footnotetext{
${ }^{29}$ The volatility of $i$ and $q$ are relevant if one considers the arguments for the smoothing of the interest rate and that (a second order approximation of) the utility function depends negatively on the variability of the terms of trade (Benigno (2004)).
} 
Foremost, the model shows that the type and degree of pass-through play an important role in the capacity of the central bank to stabilize in the short run CPI inflation but not domestic-inflation. With imperfect pass-through and some realistic interest smoothing, optimal monetary policy loses a significant part of its latitude. In particular, delayed pass-through turns out to reduce monetary policy effectiveness more than incomplete pass-through. These results contrast with conventional thinking, according to which the ability to move the exchange rate allows the central bank to stabilize CPI inflation in the short run.

Second, imperfect pass-through tends to insulate the economy from foreign shocks and monetary policy control. This is due to the lower efficiency of the DERC, which on the one hand reduces the impact of foreign shocks on import inflation. On the other hand, considering realistic monetary policies, it reduces the stabilization role played by the DERC in the transmission mechanism, and, consequently, the variability of import inflation. Two important implications are less variability of the real exchange rate in general, and more variability of CPI inflation in the case of CPI inflation-targeting but less variability of CPI inflation in the case of domestic inflation-targeting.

Third, with CPI inflation-targeting, the trade-off between CPI inflation and outputgap variabilities worsens with imperfect pass-through and this phenomenon is stronger the more monetary policy concerns with CPI inflation versus output-gap stabilization. Thus, it is important to know the type and degree of the pass-through to assess the attainable output-gap-CPI inflation variabilities trade-offs. Furthermore, combining this finding with the literature on the relationship between the pass-through and the inflation environment, a chosen variability in CPI inflation could be achieved at an output-gap variability cost much higher than expected.

Fourth, imperfect pass-through tends to reduce the volatility of the economy with domestic inflation-targeting but it worsens the trade-off between the stabilization of CPI inflation and the output-gap with CPI inflation-targeting. One important implication is that it seems better to target domestic inflation with imperfect passthrough.

Finally, interest smoothing constrains the ability of the central bank to stabilize CPI and domestic inflation in the short run.

These findings are all grounded on the fact that the pass-through affects the efficiency of the DERC in the transmission of the monetary impulse and foreign shocks.

\section{A Appendix}

\section{A.1 Parametrization}

Whenever it is possible, the structural parameters of the model are set as in Svensson (2000). They are the probability of not changing the price in the next period, $\alpha=$ 0.5 ; the output elasticity of the marginal input requirement function, $\omega=0.8$; the elasticity of substitution between varieties of the same type of good $\vartheta=1.25$; the share of import good in the composite input to produce the domestic good, $\mu=0.1$; the intertemporal elasticity of substitution, $\sigma=0.5$; the elasticity of substitution between domestic and import goods for domestic consumers, $\theta=1$ and for foreign consumers $\theta^{*}=2$; the share of import goods in domestic consumption, $w=0.3$; the share of domestic good in foreign consumption, $w^{*}=0.15$; the income elasticity of foreign real 
consumption, $\bar{\beta}_{y}^{*}=0.9$; the variance of the demand and supply shocks, $\sigma_{\eta^{d}}^{2}=\sigma_{\eta^{i}}^{2}=$ 1 , and $\sigma_{\eta^{d, n}}^{2}=\sigma_{\eta^{i, n}}^{2}=0.5$ respectively; the parameters for the exogenous variables (AR processes), $\gamma_{y}^{d, n}=\gamma_{y}^{i, n}=0.8, \gamma_{y}^{*}=\gamma_{\pi}^{*}=0.8$; the coefficients for the foreign Taylor rule, $f_{\pi}^{*}=1.5, f_{y}^{*}=0.5$; the variance of the shocks to the foreign variables, $\sigma_{\varepsilon^{*}}^{2}=\sigma_{\eta^{*}}^{2}=\sigma_{\xi^{*}}^{2}=0.5$. The new parameters introduced in the current model are chosen in the following way: the measure of the importance of habit formation in the utility function, $\widetilde{\nu}$, is set equal to 0.8 according to the estimate provided by Banerjee and Batini (2003); the degree of indexation to the previous period inflation rate, $\zeta$, is set equal to 0.66 in line with Smets and Wouters (2005).

Aggregate demand components Regarding the aggregate demand in the domestic sector, combine equation (9), (11) and (12) to obtain

$$
\widehat{Y}_{t}^{d}=C_{t}^{d}+\frac{1}{A_{t}^{d}}(1-\mu) f^{-1}\left(\widehat{Y}_{t}^{d}\right)+C_{t}^{* d}+\frac{1}{A_{t}^{i}} \mu^{i} f^{-1}\left(\widehat{Y}_{t}^{i}\right)
$$

then log-linearizing around steady state values yields

$$
\widehat{y}_{t}^{d}=k_{1} c_{t}^{d}+k_{2} \widehat{y}_{t}^{d}+k_{3} c_{t}^{* d}+k_{4} \widehat{y}_{t}^{i}
$$

where $k_{1}, k_{2}, k_{3}$ and $k_{4}$ are steady state elasticities. Since $\sum_{j=1}^{4} k_{j}=1$ and $k_{4}$ depends on $\mu^{i}$, it follows that also $k_{1}, k_{2}, k_{3}$ depend on $\mu^{i}$. Now, for $\mu^{i}=0.5$, I set $k_{1}=0.4$, $k_{2}=0.3$, and $k_{4}=0.1$ and for $\mu^{i}=0, k_{1}=0.433, k_{2}=0.333, k_{4}=0$. Then I approximate $k_{j}\left(\mu^{i}\right), j=1, . ., 4$ with linear functions passing for these points and I obtain:

$$
\begin{aligned}
& k_{1}=0.433-0.066 \mu^{i}, \\
& k_{2}=0.333-0.066 \mu^{i} \\
& k_{4}=0.2 \mu^{i} \\
& k_{3}=1-k_{1}-k_{2}-k_{4}
\end{aligned}
$$

Then, substituting into (30) yields

$\widehat{y}_{t}^{d}=\left[0.666+0.066 \mu^{i}\right]^{-1}\left[\left(0.433-0.066 \mu^{i}\right) c_{t}^{d}+0.2 \mu^{i} \widehat{y}_{t}^{i}+\left(1-0.766-0.068 \mu^{i}\right) c_{t}^{* d}\right]$,

which can be rewritten as

$$
\widehat{y}_{t}^{d}=\kappa_{1}\left(\mu^{i}\right) c_{t}^{d}+\kappa_{2}\left(\mu^{i}\right) \widehat{y}_{t}^{i}+\kappa_{3}\left(\mu^{i}\right) c_{t}^{* d},
$$

where

$$
\begin{aligned}
\kappa_{1} & \equiv\left(0.433-0.066 \mu^{i}\right)\left[0.666+0.066 \mu^{i}\right]^{-1}, \\
\kappa_{2} & \equiv\left(0.2 \mu^{i}\right)\left[0.666+0.066 \mu^{i}\right]^{-1}, \\
\kappa_{3} & \equiv\left(1-0.766-0.068 \mu^{i}\right)\left[0.666+0.066 \mu^{i}\right]^{-1} .
\end{aligned}
$$

As to the aggregate demand in the import sector, I set the $\widetilde{\kappa}=0.1$. 


\section{A.2 State-space form of the model}

The model in state-space form is

$$
\begin{gathered}
\operatorname{Min}_{\left\{i_{t+\tau \mid t}\right\}_{\tau=0}^{\infty} E_{t} \sum_{\tau=0}^{\infty} \beta^{\tau} Y_{t+\tau}^{\prime} K Y_{t+\tau}} \\
\text { subject to }\left[\begin{array}{c}
X_{t+1} \\
x_{t+1 \mid t}
\end{array}\right]=A\left[\begin{array}{c}
X_{t} \\
x_{t}
\end{array}\right]+B i_{t}+B^{1} i_{t+1 \mid t}+\left[\begin{array}{c}
v_{t+1} \\
0
\end{array}\right] \\
\cdot \\
\text { where } Y_{t} \equiv C_{Z}\left[\begin{array}{c}
X_{t} \\
x_{t}
\end{array}\right]+C_{i} i_{t}
\end{gathered}
$$

where

$$
\begin{aligned}
Y_{t} & =\left(\pi_{t}^{c}, \pi_{t}^{d}, y_{t}^{d}, i_{t}-i_{t-1}\right)^{\prime} \\
X_{t} & =\left(\pi_{t}^{d}, \pi_{t+1 \mid t}^{d}, \pi_{t-1}^{i}, \pi_{t}^{*}, y_{t}^{d}, y_{t}^{i}, y_{t}^{*}, i_{t}^{*}, y_{t}^{d, n}, y_{t}^{i, n}, i_{t-1}, q_{t-1}, q_{t-1}^{i}\right)^{\prime} \\
x_{t} & =\left(\pi_{t}^{i}, q_{t}^{i}, \rho_{t}, \pi_{t+2 \mid t}^{d}\right)^{\prime} .
\end{aligned}
$$

Denoting the dimensions of $X_{t}, x_{t}, Y_{t}$, by $n_{1}, n_{2}, n_{3}$ and letting $n \equiv n_{1}+n_{2}$, it follows that $K$ is a $n_{3} x n_{3}$ diagonal matrix with the diagonal $\left(\mu^{c}, \mu^{d}, \lambda, \nu\right)$ and off-diagonal elements equal to zero, $A$ is a $n x n$ matrix, $B$ and $B_{1}$ are $n x 1$ column vectors, $C_{Z}$ is a $n_{3} x n_{3}$ matrix and $C_{i}$ is a $n_{3} x 1$ column vector.

To write the model in state-space form note that

$$
\begin{aligned}
\pi_{t+2 \mid t+1}^{d} & =\pi_{t+2 \mid t}^{d}+\frac{\zeta}{1+\zeta} \varepsilon_{t+1}, \\
\rho_{t+1 \mid t} & =\rho_{t}-i_{t}+\pi_{t+1 \mid t}^{d}, \\
q_{t+1 \mid t} & =q_{t}+\pi_{t+1 \mid t}^{i}-\pi_{t+1 \mid t}^{d} .
\end{aligned}
$$

Then, take the expectation in period $t$ of equation (21) and solve it for $\pi_{t+3 \mid t}^{d}$,

$$
\pi_{t+3 \mid t}^{d}=(1+\zeta) \pi_{t+2 \mid t}^{d}-\zeta \pi_{t+1 \mid t}^{d}-\xi\left[\omega y_{t+2 \mid t}^{d}+\mu q_{t+2 \mid t}\right]
$$

where $\xi \equiv \frac{(1-\alpha)^{2}}{\alpha(1+\omega \vartheta)}$. Next, lead equation (15) one period and take the expectation in period $t$. Then apply the same procedure to (31), (32) and (22) and substitute for $\rho_{t+2 \mid t}, q_{t+2 \mid t}$ and $\pi_{t+2 \mid t}^{i}$ in the equation for $y_{t+2 \mid t}^{d}$. This gives

$$
\begin{aligned}
y_{t+2 \mid t}^{d} & =\beta_{y} y_{t+1 \mid t}^{d}-\beta_{\rho} \rho_{t+1 \mid t}+\beta_{\rho} i_{t+1 \mid t}-\left(\beta_{\rho}+\beta_{q}\right) \pi_{t+2 \mid t}^{d}+\left(\beta_{q}-\beta_{q-1}\right) q_{t}+\left[\beta_{q}(2+\zeta)-\beta_{q-1}\right] \pi_{t+1 \mid t}^{i} \\
& -\left(\beta_{q}-\beta_{q-1}\right) \pi_{t+1 \mid t}^{d}-\beta_{q} \zeta \pi_{t}^{i}-\beta_{q} \xi^{i} \omega y_{t+1 \mid t}^{i}-\beta_{q} \xi^{i} q_{t+1 \mid t}^{i}+\beta_{y^{*}} y_{t+1 \mid t}^{*}+\beta_{y^{n}} y_{t+1 \mid t}^{d, n},
\end{aligned}
$$


where $\xi^{i} \equiv \frac{(1-\alpha)^{2}}{\alpha(1+\omega \vartheta)}$. Finally, substitute for $y_{t+2 \mid t}^{d}$ and $q_{t+2 \mid t}$ in (33). This gives

$$
\begin{aligned}
\pi_{t+3 \mid t}^{d} & =\left[1+\zeta+\xi \omega\left(\beta_{\rho}+\beta_{q}\right)+\xi \mu\right] \pi_{t+2 \mid t}^{d}+\left[\xi \mu-\zeta+\xi \omega\left(\beta_{q}-\beta_{q-1}\right)\right] \pi_{t+1 \mid t}^{d} \\
& +\left(\xi \omega \beta_{q} \xi^{i}+\xi \mu \xi^{i}\right) q_{t+1 \mid t}^{i}-\xi\left[\omega\left(\beta_{q}(2+\zeta)-\beta_{q-1}\right)+\mu(1+\zeta)+\mu\right] \pi_{t+1 \mid t}^{i} \\
& -\xi \omega \beta_{y} y_{t+1 \mid t}^{d}+\xi \omega \beta_{\rho} \rho_{t+1 \mid t}-\xi \omega \beta_{\rho} i_{t+1 \mid t}+\xi \zeta\left(\omega \beta_{q}+\mu\right) \pi_{t}^{i} \\
& +\omega \xi \xi^{i}\left(\omega \beta_{q}+\mu\right) y_{t+1 \mid t}^{i}-\omega \xi \beta_{y^{*}} y_{t+1 \mid t}^{*}-\omega \xi \beta_{y^{n}} y_{t+1 \mid t}^{d, n}-\xi\left[\omega\left(\beta_{q}-\beta_{q-1}\right)+\mu\right] q_{t} .
\end{aligned}
$$

It follows that

$$
A=\left[\begin{array}{c}
e_{2} \\
e_{17} \\
e_{n_{1}+1} \\
\gamma_{\pi}^{*} e_{4} \\
\beta_{y} e_{5}-\beta_{\rho} A_{n_{1}+3}+\beta_{q}\left(A_{12}+A_{n_{1}+1}-A_{1}\right)-\beta_{q_{-1}} A_{12}+\beta_{y^{*}} e_{7}+\beta_{y^{n}} e_{9} \\
\beta_{y} e_{6}-\beta_{\rho}^{i} A_{n_{1}+3}+\beta_{q}^{i}\left(A_{12}+A_{n_{1}+1}-A_{1}\right)+\beta_{q_{-1}}^{i} A_{12}+\beta_{y^{*}}^{i} e_{7}+\beta_{y^{n}}^{i} e_{10} \\
\gamma_{y}^{*} e_{7} \\
f_{\pi}^{*} \gamma_{\pi}^{*} e_{4}+f_{y}^{*} \gamma_{y}^{*} e_{7} \\
\gamma_{y}^{d, n} e_{9} \\
\gamma_{y}^{i, n} e_{10} \\
e_{0} \\
e_{12}+A_{3}-e_{1} \\
e_{n_{1}+2} \\
-\xi^{i}\left(\omega e_{6}+e_{n_{1}+2}-\zeta e_{3}+(1+\zeta) e_{n_{1}+1}\right. \\
e_{n_{1}+2}+\mu^{i} e_{2}-A_{n_{1}+1}-\left(1-\mu^{i}\right)\left(e_{8}-A_{4}\right) \\
e_{n_{1}+3}+e_{2} \\
A_{n}
\end{array}\right],
$$

where $e_{j}, j=0, \ldots, n$ stands for a $1 \mathrm{x} n$ row vector that for $j=0$ has all the elements equal to zero and for $j \neq 0$ has element $j$ equal to unity and all other elements equal to zero; $A_{j}$ stands for row $j$ of the matrix $A$ and

$$
\begin{aligned}
A_{n} & =\left[1+\zeta+\xi \omega\left(\beta_{\rho}+\beta_{q}\right)+\xi \mu\right] e_{n}+\left[\xi \mu-\zeta+\xi \omega\left(\beta_{q}-\beta_{q-1}\right)\right] A_{1} \\
& +\left(\xi \omega \beta_{q} \xi^{i}+\xi \mu \xi^{i}\right) A_{n_{1}+2}-\xi\left[\omega\left(\beta_{q}(2+\zeta)-\beta_{q-1}\right)+\mu(1+\zeta)+\mu\right] A_{n_{1}+1} \\
& -\xi \omega \beta_{y} A_{5}+\xi \omega \beta_{\rho} A_{n_{1}+3}+\xi \zeta\left(\omega \beta_{q}+\mu\right) e_{n_{1}+1} \\
& +\omega \xi \xi^{i}\left(\omega \beta_{q}+\mu\right) A_{6}-\omega \xi \beta_{y^{*}} A_{7}-\omega \xi \beta_{y^{n}} A_{9}-\xi\left[\omega\left(\beta_{q}-\beta_{q-1}\right)+\mu\right] A_{12} .
\end{aligned}
$$

Finally the vectors $B$ and $B^{1}$ are given by 


$$
B=\left[\begin{array}{c}
0 \\
0 \\
0 \\
0 \\
\beta_{\rho} \\
\beta_{\rho}^{i} \\
0 \\
0 \\
0 \\
0 \\
1 \\
0 \\
0 \\
0 \\
\left(1-\mu^{i}\right) \\
-1
\end{array}\right], B^{1}=\left[\begin{array}{c}
0 \\
0 \\
0 \\
0 \\
0 \\
0 \\
0 \\
0 \\
0 \\
0 \\
0 \\
0 \\
0 \\
0 \\
0 \\
0 \\
-\xi \omega \beta_{\rho}\left(1+\beta_{y}\right)+\xi \xi^{i}\left(\omega \beta_{q}+\mu\right)\left(1-\mu^{i}\right)+\xi \xi^{i} \omega\left(\beta_{q} \omega+\mu\right) \beta_{\rho}^{i}
\end{array}\right]
$$

At this point, I used the algorithm developed by Oudiz and Sachs (1985) as well as by Backus and Driffil (1986) for the solution of the optimization problem in the dynamic programming framework; a detailed description is provided by Soderlind (1998) and (1999). For the problem raised by the presence of future controls, see the working paper version of Svensson (2000).

\section{References}

Abel, A.B. (1990), "Asset Prices under Habit Formation and Catching up with the Joneses". American Economic Review Papers and Proceedings 80: 38 - 42.

Bacchetta P. and E. Wincoop (2002), "A Theory of the Currency Denomination of International Trade", NBER Working paper No.9039.

Backus D. and J. Driffill (1986), "The Consistency of Optimal Policy in Stochastic Rational Expectations Models", CEPR Discussion Paper No.124.

Bakhshi H, Khan H. and B.Rudolf (2004) "The Phillips curve under statedependent pricing", Bank of England Quarterly Bulletin, Autumn 2004.

Bailliu J and E. Fujii, (2004). "Exchange Rate Pass-Through and the Inflation Environment in Industrialized Countries: An Empirical Investigation," Working Papers 04-21, Bank of Canada

Ball L., "Policy Rules for Open Economies", in John B. Taylor, ed., Monetary Policy Rules. Chicago, Illinois: university of Chicago Press, 1999, pp 127-144.

Banerjee R. and N. Batini (2003), "UK Consumers' Habits", Discussion Paper No. 13, Bank of England.

Benigno P. (2004), "Optimal Monetary Policy in a Currency Area", Journal of International Economics, 63, 293-320.

Betts C. and M. Devereux (2000), "Exchange Rate Dynamics in a Model of Pricing to Market", Journal of International Economics, 50, 215-244. 
Burstein, A. T, Neves, J., Rebelo, S., (2003) "Distribution costs and real exchange rate dynamics during exchange-rate-based stabilizations", Journal of Monetary Economics, September, 1189-1214.

Calvo, Guillermo (1983), "Staggered Prices in a Utility-Maximizing Framework," Journal of Monetary Economics 12, 983-998.

Campa J., and L. Goldberg (2002), "Exchange Rate Pass-through into Import Prices: a Macro and Micro Phenomenon", NBER Working Paper No. 8934.

Christiano, Lawrence J., Martin Eichenbaum, and Charles L. Evans (2001) "Nominal Rigidities and the Dynamic Effects of a shock to monetary policy", NBER Working Paper No. 8403.

Chudhry, E. and D. Hakura (2001), "Exchange Rate Pass-through to Domestic Prices: Does the Inflationary Environment Matter?" IMF Working paper No. $\mathrm{WP} / 01 / 194$.

Clarida R., Gali J. and M. Gertler (2002), "A Simple Framework for International Monetary Policy Analysis", NBER Working paper No. 8870.

Corsetti G. and L Dedola (2004), "Macroeconomics of International Price Discrimination", Forthcoming Journal of International Economics.

Corsetti G. and P. Pesenti (2004), "International Dimensions of Optimal Monetary Policy", Journal of Monetary Economics, 52/2 pp 281-30.

Currie, David, and Paul Levine (1993), "Rules, Reputation and Macroeconomic Policy Coordination", Cambridge University Press, Cambridge.

Devereux M. (2001), "Monetary Policy, Exchange Rate Flexibility and Exchange Rate Pass-through", Bank of Canada Conference Revisiting the Case for Flexible Exchange Rates.

Devereux M. and C. Engel (2001), "Endogenous Currency of Price Setting in a Dynamic Open Economy Model", NBER Working Paper No.8559.

Devereux M., Lane P and J. Xu (2004), "Exchange Rates and Monetary Policy in Emerging Market Economies", IIIS Discussion Paper No.36.

Devereux M. and J. Yetman (2002), "Price Setting and Exchange Rate PassThrough: Theory and Evidence. "In Price Adjustment and Monetary Policy, 347-71. Proceedings of a conference held at the Bank of Canada, November 2002.

Devereux M., C. Engel and P. Storggaard (2004), "Endogenous exchange rate Pass-Through when Nominal Prices Are Set in Advance", Journal of International Economics 63, 263- 291.

Engel C. (2002), "The Responsiveness of Consumer Prices to Exchange Rates: A Synthesis of some New Open-Economy Macro Models". 
Fuhrer, J. C. (2000). "Habit Formation in Consumption and its Implications for Monetary Policy Models." American Economic Review, 90: 367-390.

Kara , A. and E. Nelson, (2002), "The Exchange Rate and Inflation in the UK", Discussion Paper No. 12, Bank of England.

Knetter, M. N., (1989), "Price Discrimination by US and German Exporters", American Economic Review 79, 198-210.

—, (1993), "International Comparison of Pricing to Market Behavior", American Economic Review 83, 473-486.

Krugman, P. R., 1987 "Pricing to Market when the Exchange Rate Changes" in Arndt, S.W. and J. D. Richardson (eds.) Real-Financial Linkages Among Open Economies, MIT Press, Cambridge.

Lane P. and G. Ganelli (2002), "Dynamic General Equilibrium Analysis: The Open Economy Dimension", in S. Altug, J. Chaddha, C. Nolan, eds., Elements in Dynamic Macroeconomic Analysis, Cambridge university press, forthcoming.

Obstfeld M. and K. Rogoff (2000), "New Directions for Stochastic Open Economy Models" Journal of International Economics, 50, 117-53.

Oudis G. and J. Sachs (1985), "International Policy Coordination in Dynamic Macroeconomic Models" in W. H. Buiter and R. C. Marston, eds., International Economic Policy Coordination, Cambridge University Press, Cambridge.

Smets F. and R. Wouters (2005), "Comparing Shocks and Frictions in US and Euro Business Cycle: A Bayesian DSGE Approach", Journal of Applied Econometrics, 20(1), January 2005.

Smets F. and R. Wouters (2002), "Openess, Imperfect Exchange Rate Passthrough and Monetary Policy", Journal of monetary Economics, 2002, Vol 49.

Soderlind P., (1998), "Optimal Time-Consistent Policy in Linear RE Models", Lecture notes.

—, (1999), "Solution and estimation of RE macromodels with optimal policy", European Economic Review 43, 813-823.

Sutherland A. (2005), "Incomplete pass-through and the welfare effects of exchange rate variability" Journal of International Economics, 65, 375-399

Svensson, L. E. O. (1997), "Inflation Forecast Targeting: Implementing and monitoring inflation targets" European Economic Review 41, 1111-1146.

—, (1998a), "Open-Economy Inflation Targeting" Working Paper, Institute for International Economic Studies.

_ (1998b), "Inflation Targeting as a Monetary Policy Rule" Journal of Monetary Economics 43, 607-654. 
(2000), "Open-Economy Inflation Targeting" Journal of International Economics 50, 155-183.

- (2003), "What is Wrong with Taylor Rules? Using Judgment in Monetary Policy through Targeting Rules," Journal of Economic Literature 41, 426-477.

— (2005), "A Framework for Monetary Policy Analysis", Lecture notes.

Taylor J. (2000), "Low Inflation, Pass-through, and the Pricing Power of Firms" European Economic Review 44, 1389-1408.

Woodford M. (2003), "Interest and Prices", Princeton University Press, Princeton and Oxford. 

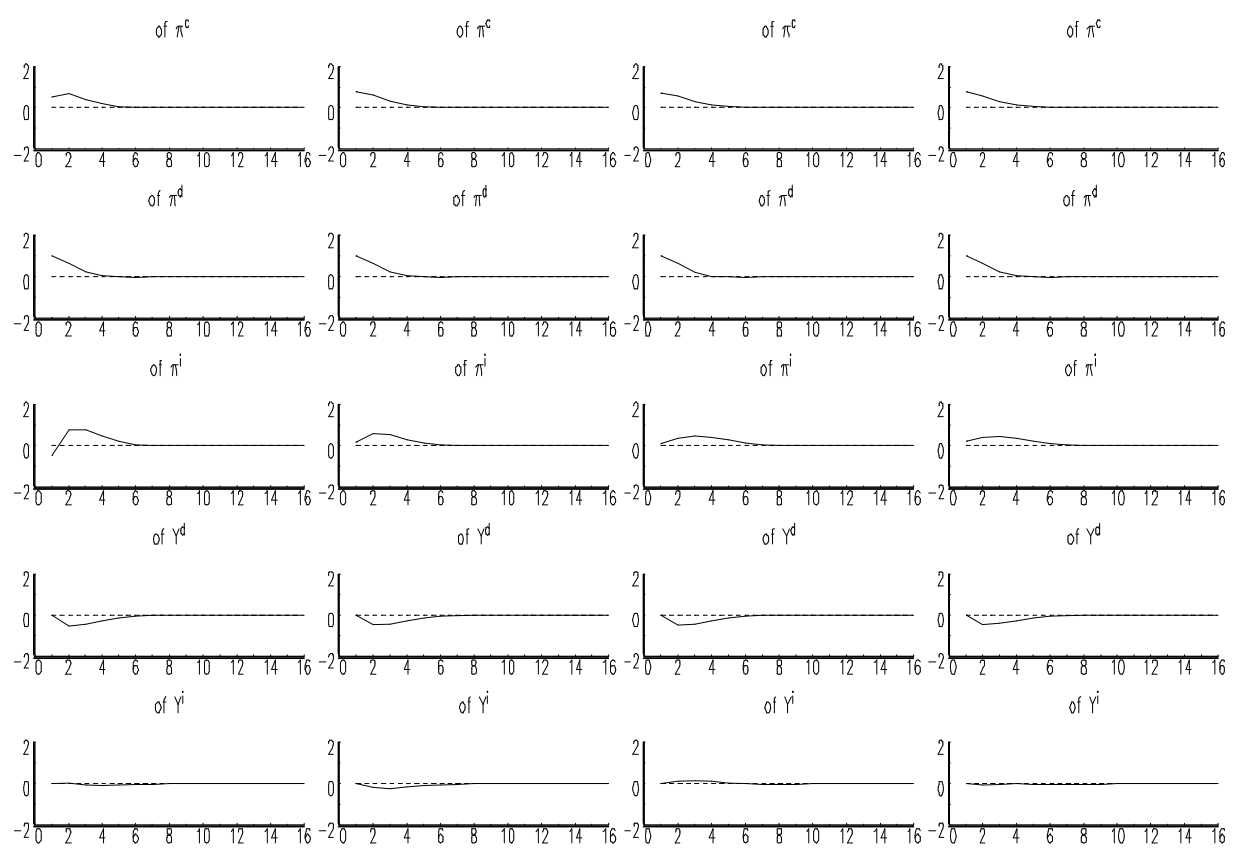

of $\mathrm{i}$

of $\mathrm{i}$

of $\mathrm{i}$
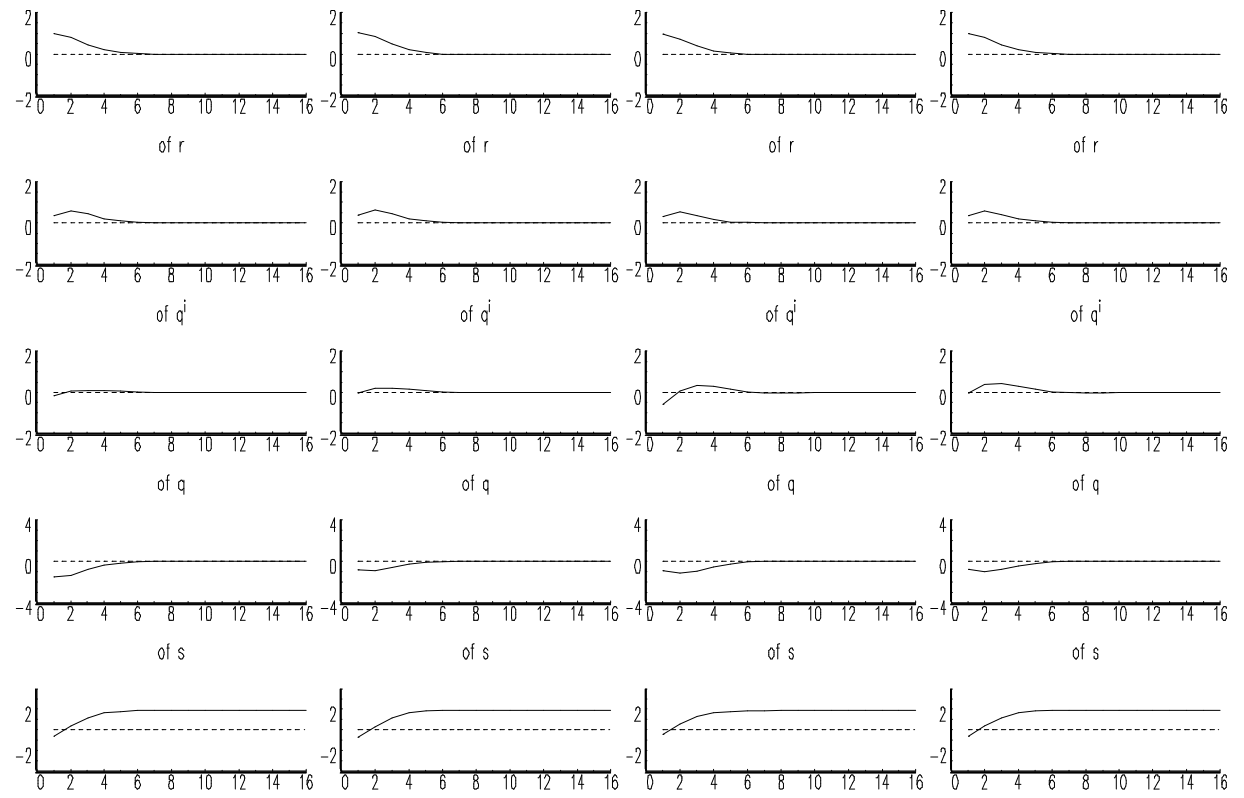

Figure 3. Strict domestic inflation-targeting. IRF to a cost-push shock. In the first, second, third and fourth column, $\alpha^{i}$ and $\mu^{i}$ are equal, respectively, to $(0.05,0)$, $(0.05,0.5),(0.5,0)$ and $(0.5,0.5)$. 

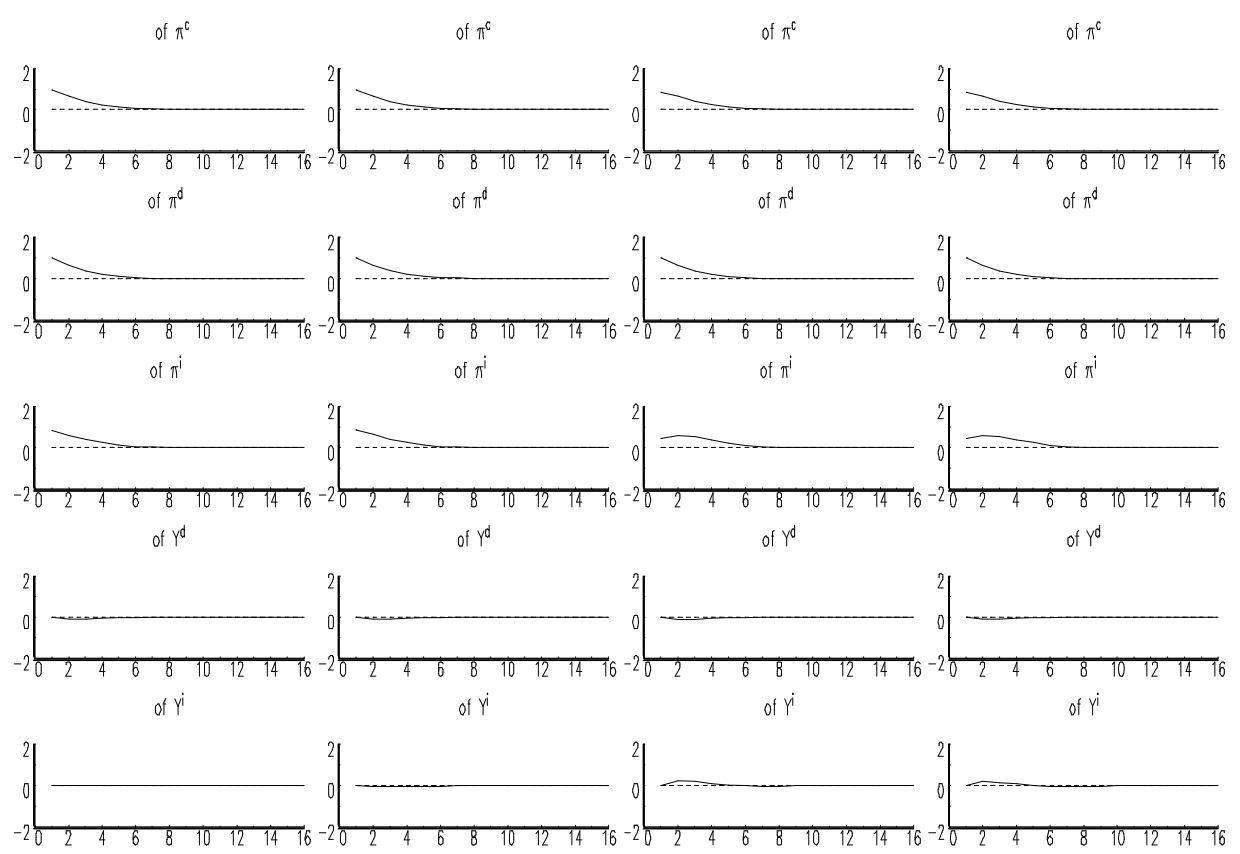

of $i$

of $\mathrm{i}$

of $\mathrm{i}$

of $\mathrm{i}$
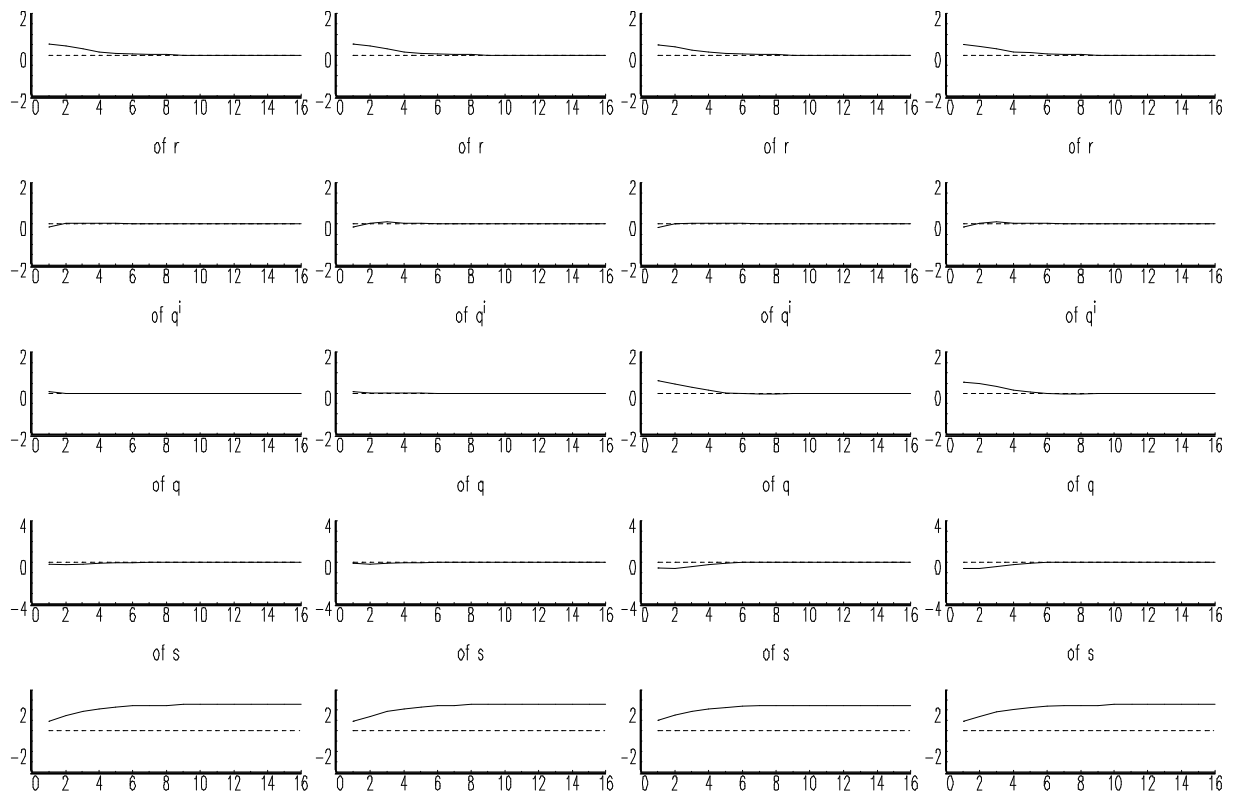

Figure 4. Flexible domestic inflation-targeting. IRF to a cost-push shock. In the first, second, third and fourth column, $\alpha^{i}$ and $\mu^{i}$ are equal, respectively, to $(0.05,0)$, $(0.05,0.5),(0.5,0)$ and $(0.5,0.5)$. 

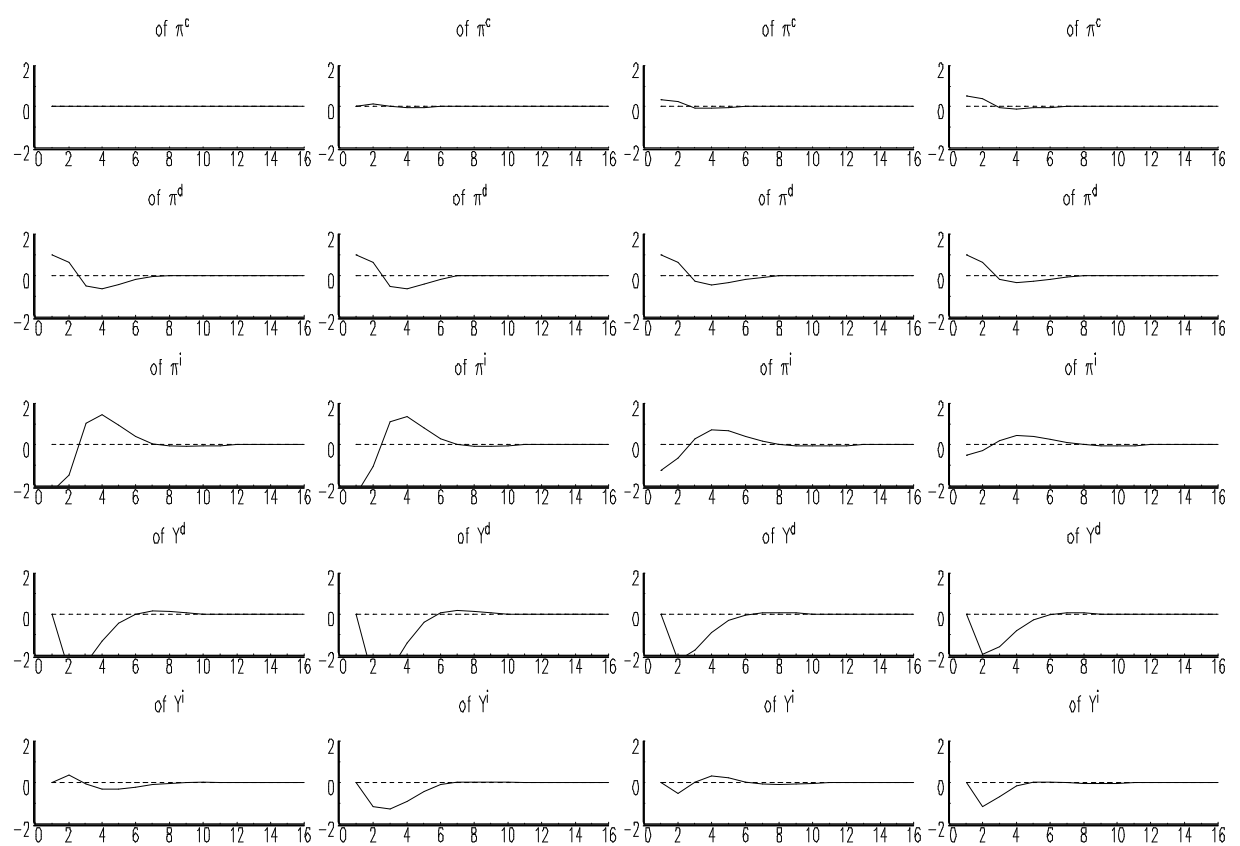

of $\mathrm{i}$

of i

of $i$

of $\mathrm{i}$
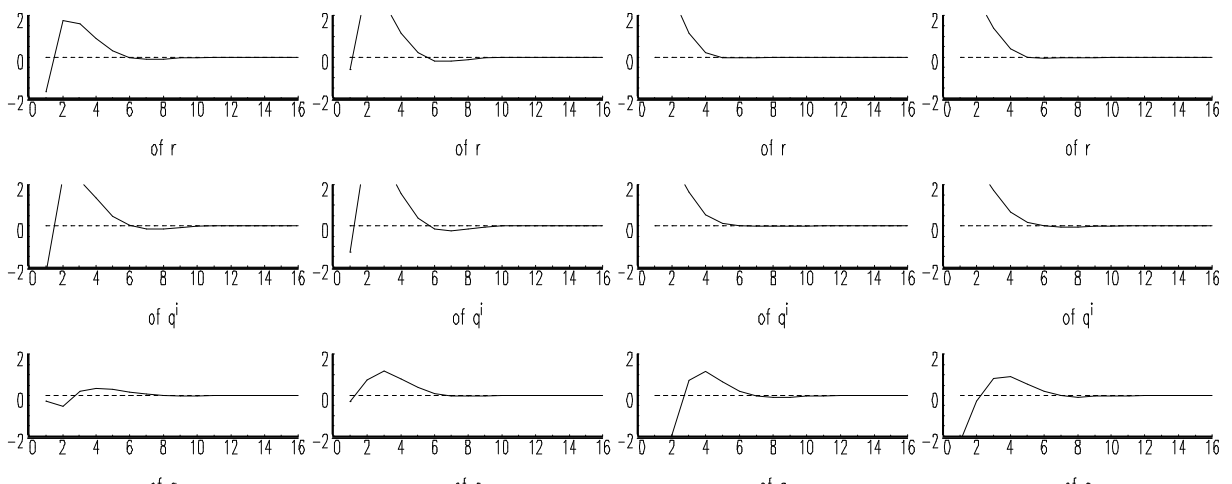

of $\mathrm{q}$

of $q$
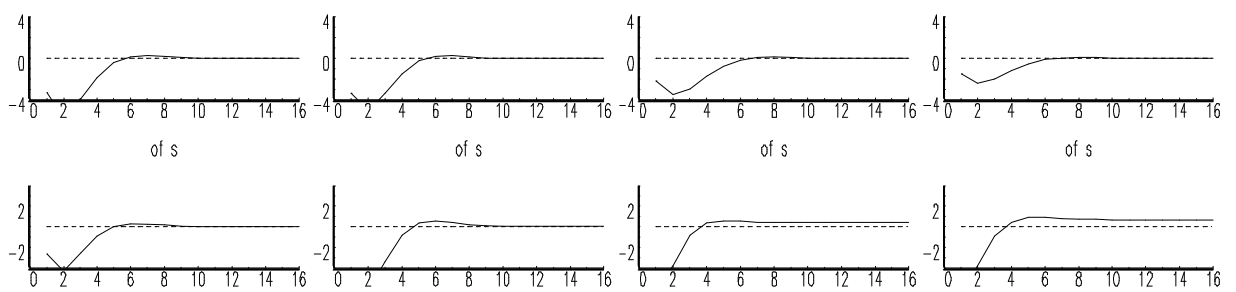

Figure 5. Strict CPI inflation-targeting. IRF to a cost-push shock. In the first, second, third and fourth column, $\alpha^{i}$ and $\mu^{i}$ are equal, respectively, to $(0.05,0)$, $(0.05,0.5),(0.5,0)$ and $(0.5,0.5)$. 

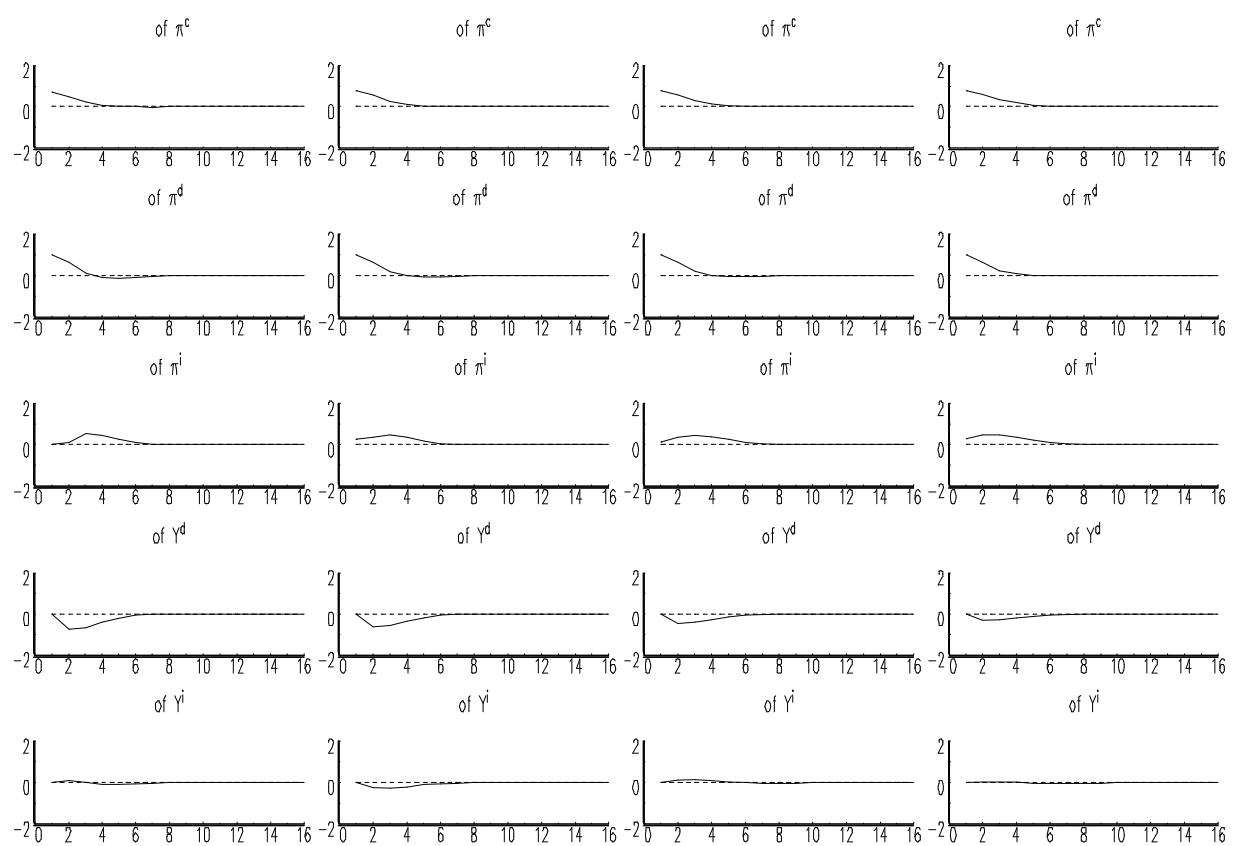

of $\mathrm{i}$

of $i$

of $\mathrm{i}$

of $\mathrm{i}$
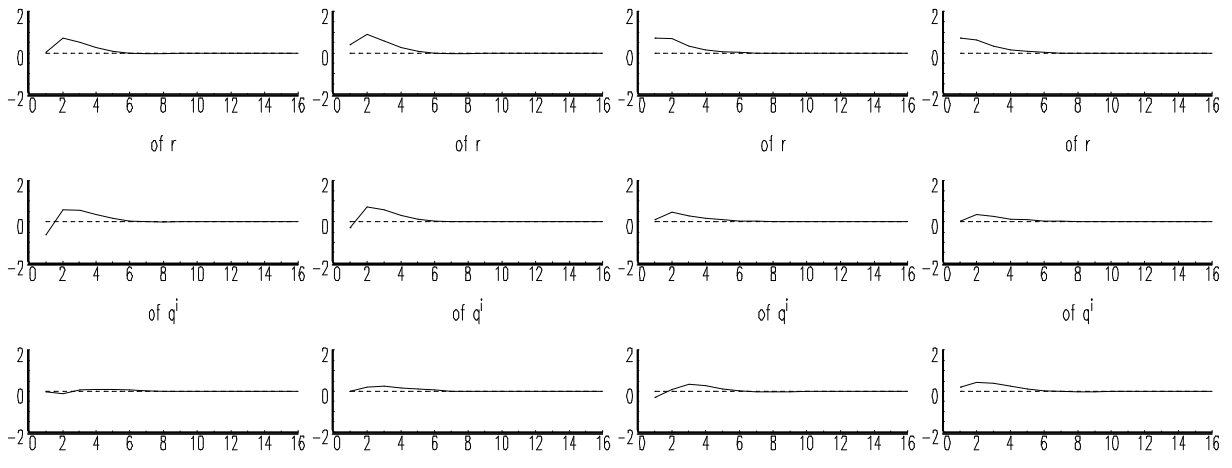

of $q$

of $q$

of 9

of 9
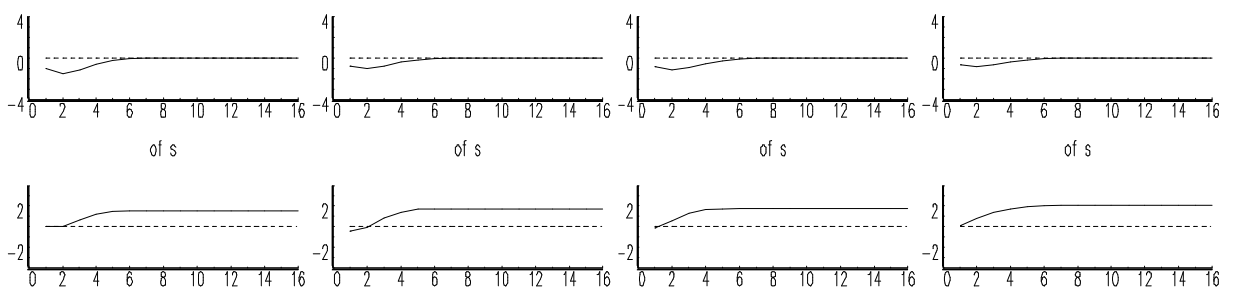

Figure 6. Flexible CPI inflation-targeting. IRF to a cost-push shock. In the first, second, third and fourth column, $\alpha^{i}$ and $\mu^{i}$ are equal, respectively, to $(0.05,0)$, $(0.05,0.5),(0.5,0)$ and $(0.5,0.5)$. 

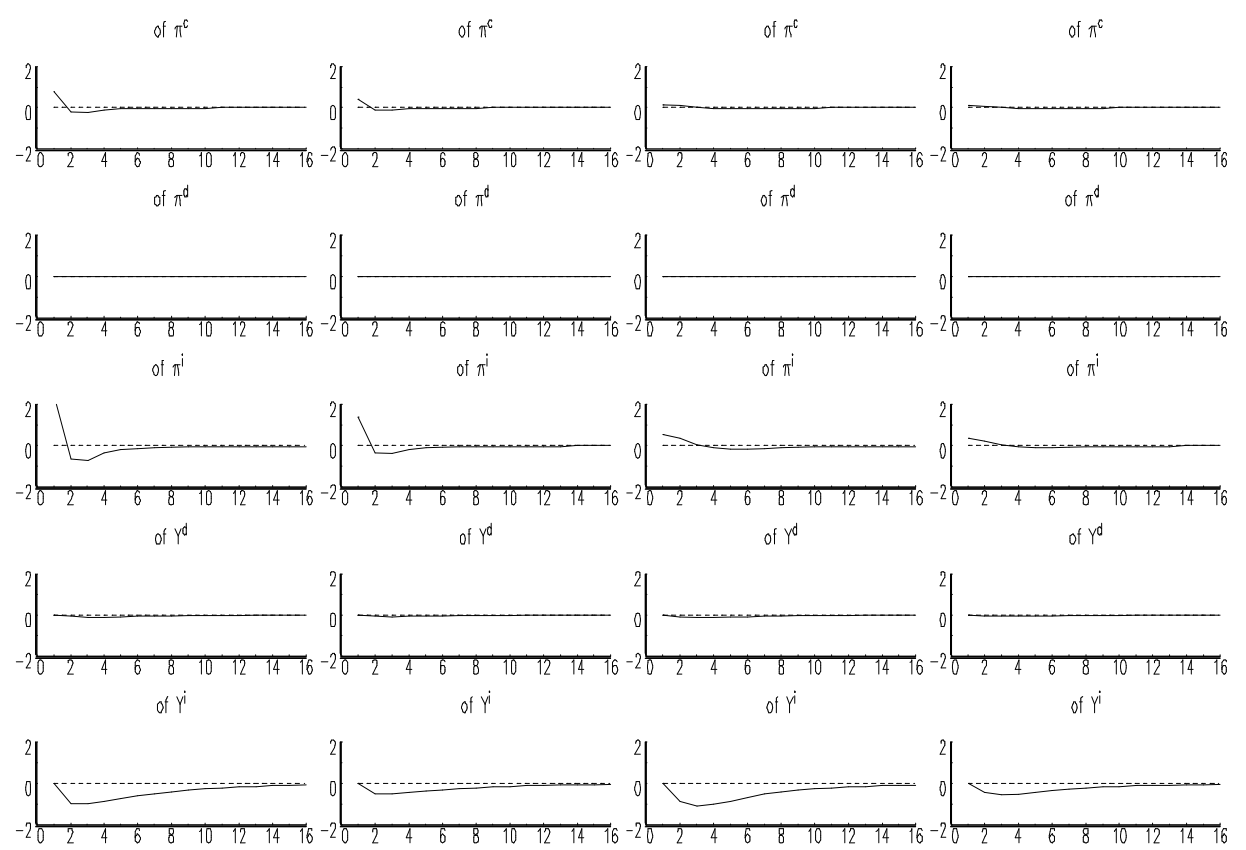

of $i$

of $\mathrm{i}$
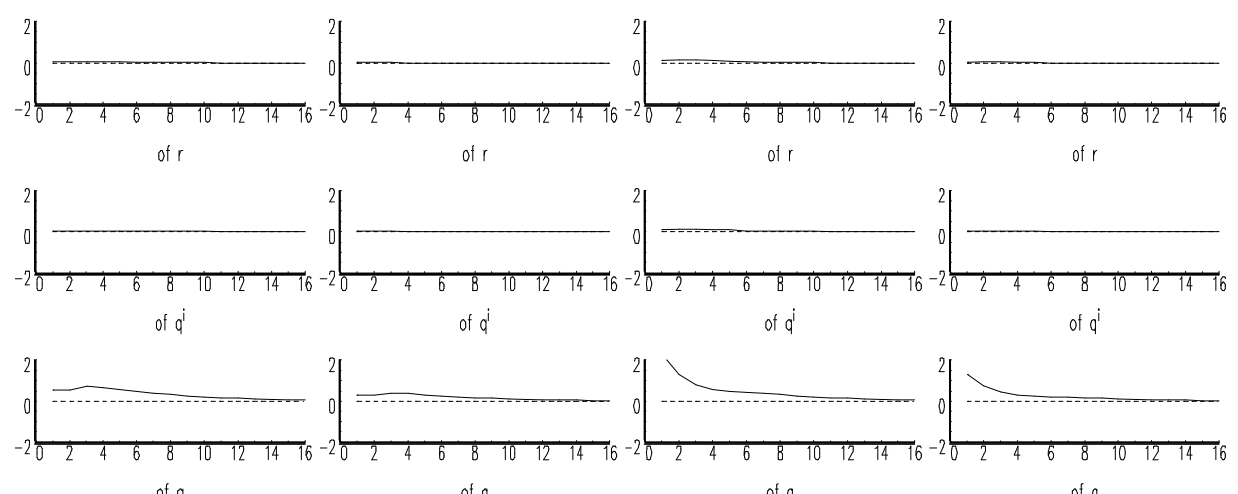

of 0
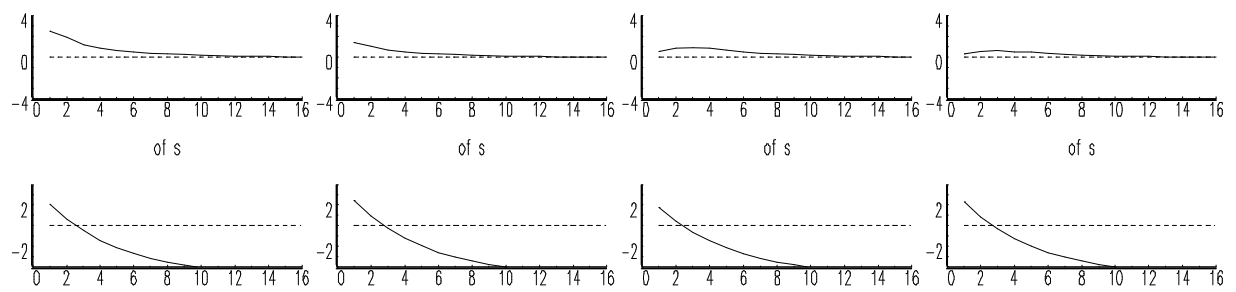

Figure 7. Strict domestic inflation-targeting. IRF to a foreign inflation shock. In the first, second, third and fourth column, $\alpha^{i}$ and $\mu^{i}$ are equal, respectively, to $(0.05,0),(0.05,0.5),(0.5,0)$ and $(0.5,0.5)$. 

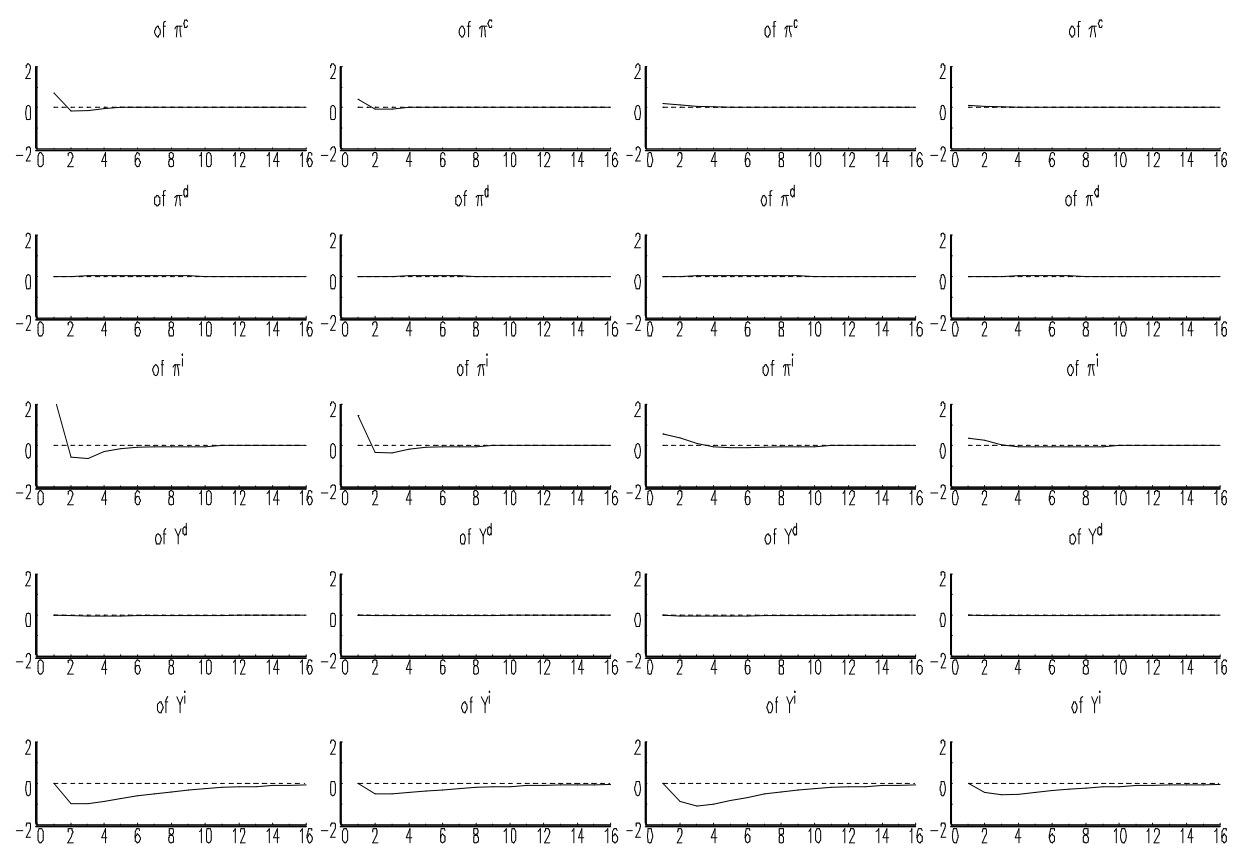

of $\mathrm{i}$

of $\mathrm{i} \quad$ of $\mathrm{i}$
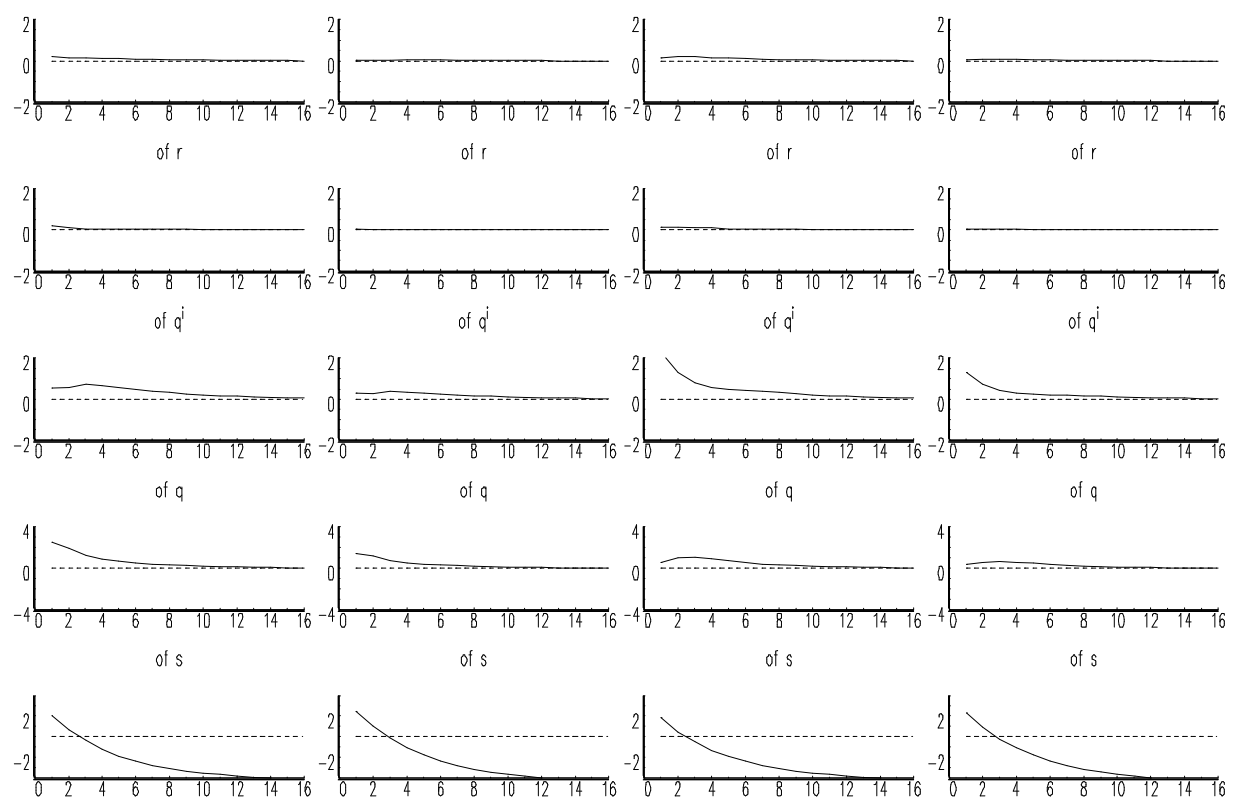

Figure 8. Flexible domestic inflation-targeting. IRF to a foreign inflation shock. In the first, second, third and fourth column, $\alpha^{i}$ and $\mu^{i}$ are equal, respectively, to $(0.05,0),(0.05,0.5),(0.5,0)$ and $(0.5,0.5)$. 

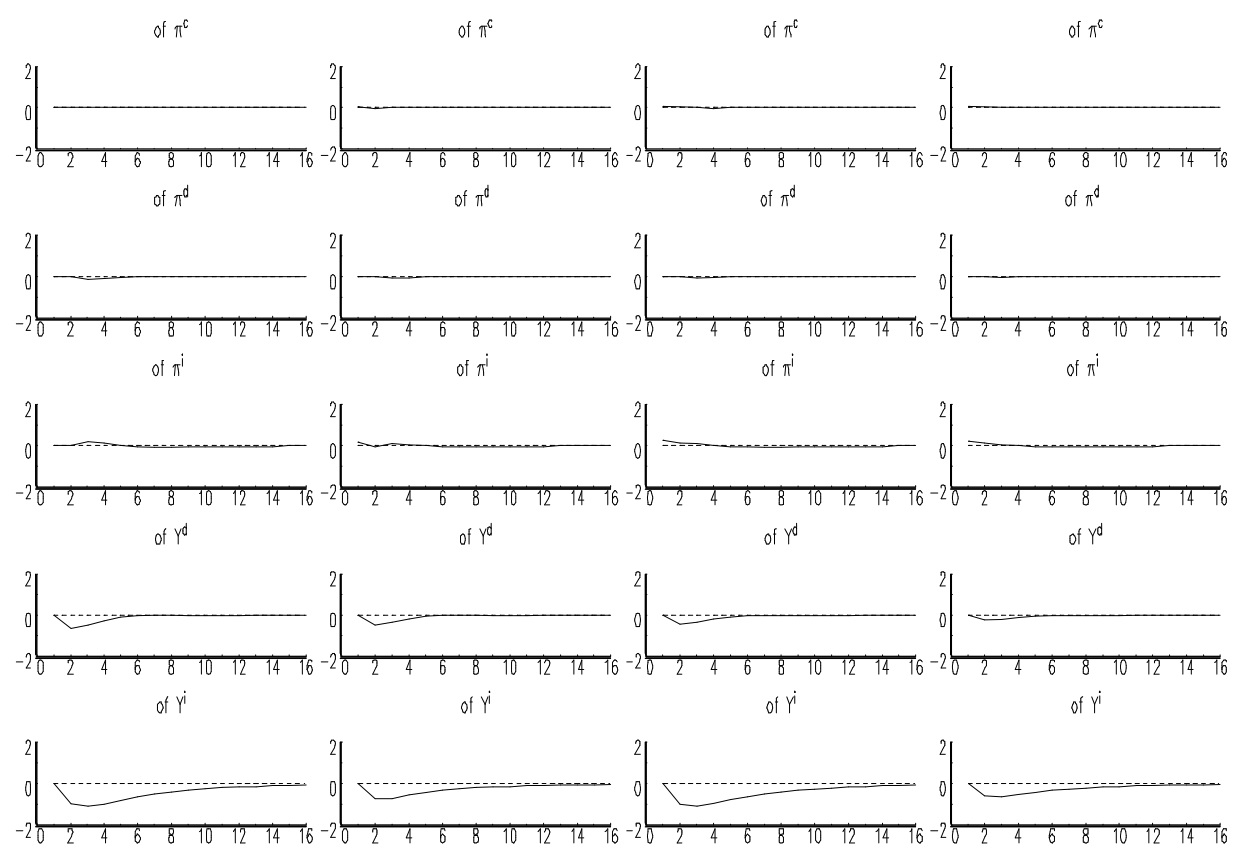

of $\mathrm{i}$

of $\mathrm{i}$

of $\mathrm{i}$
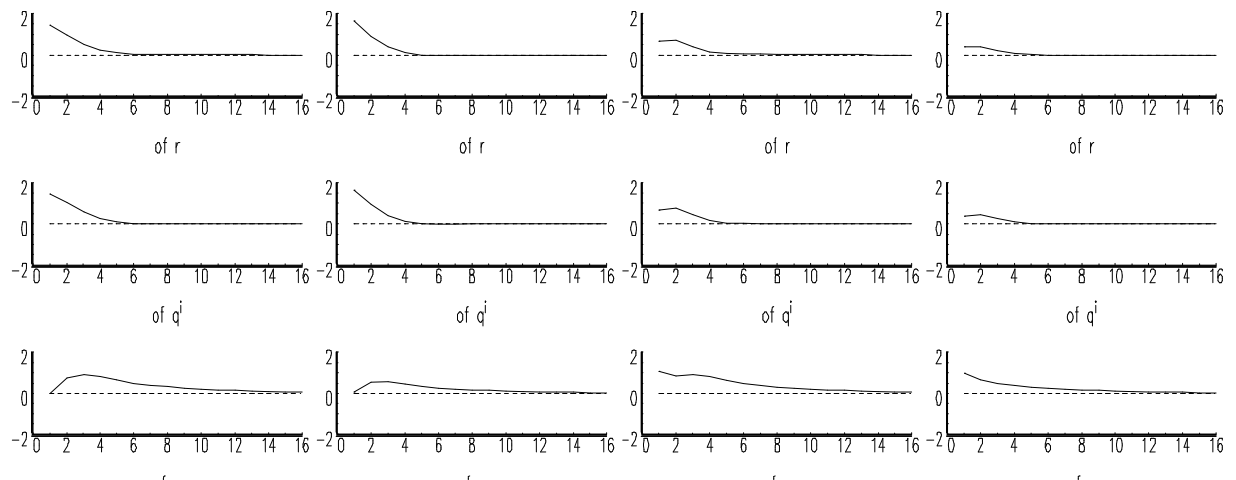

of $\mathrm{q}$

of $q$

of 9

of 9
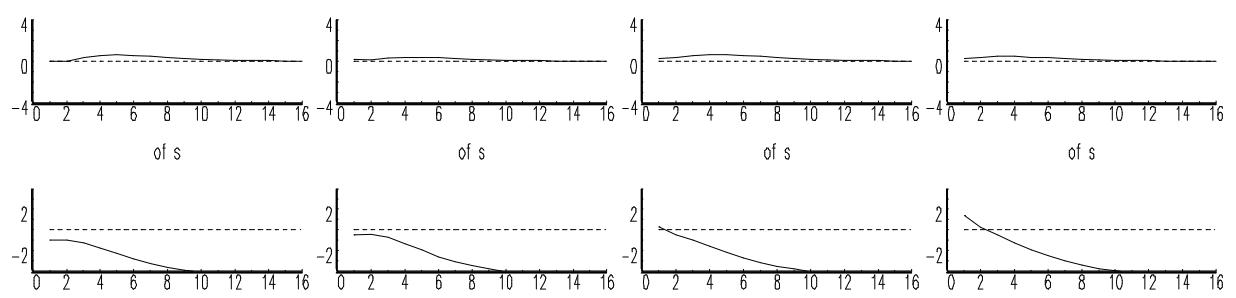

Figure 9. Strict CPI inflation-targeting. IRF to a foreign inflation shock. In the first, second, third and fourth column, $\alpha^{i}$ and $\mu^{i}$ are equal, respectively, to $(0.05,0)$, $(0.05,0.5),(0.5,0)$ and $(0.5,0.5)$. 

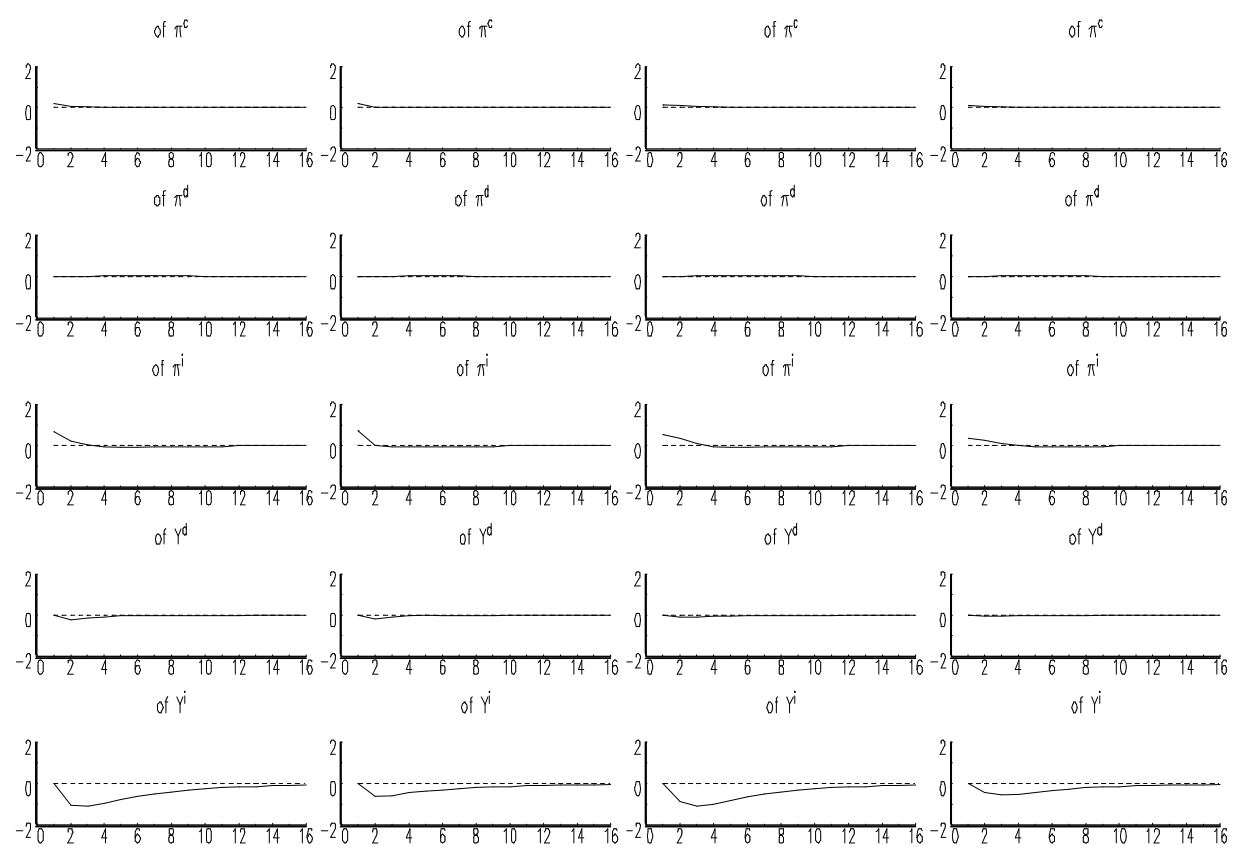

of $\mathrm{i}$

of $\mathrm{i}$ of $\mathrm{i}$
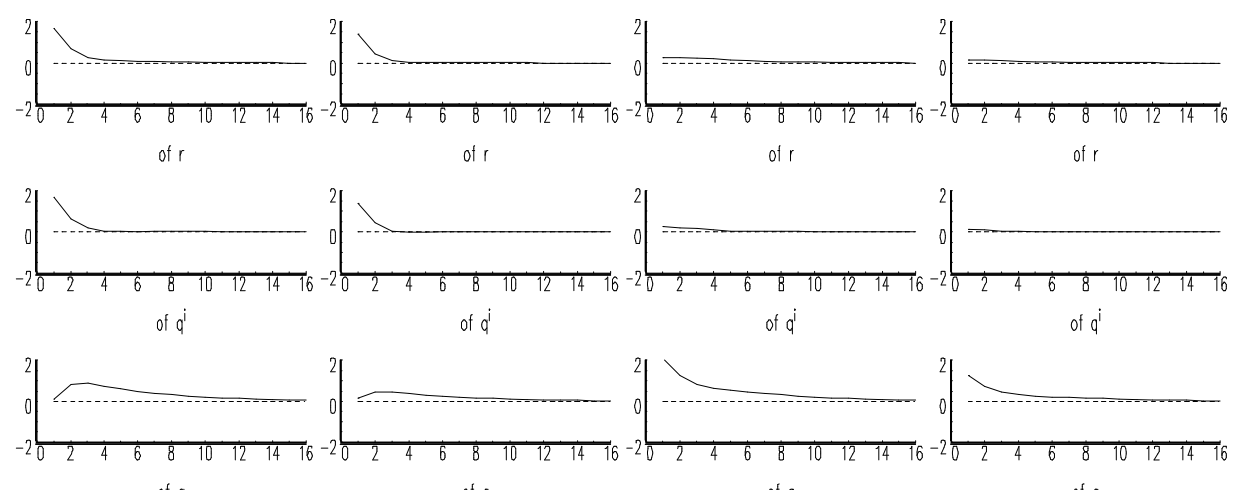

of 0

of $q$
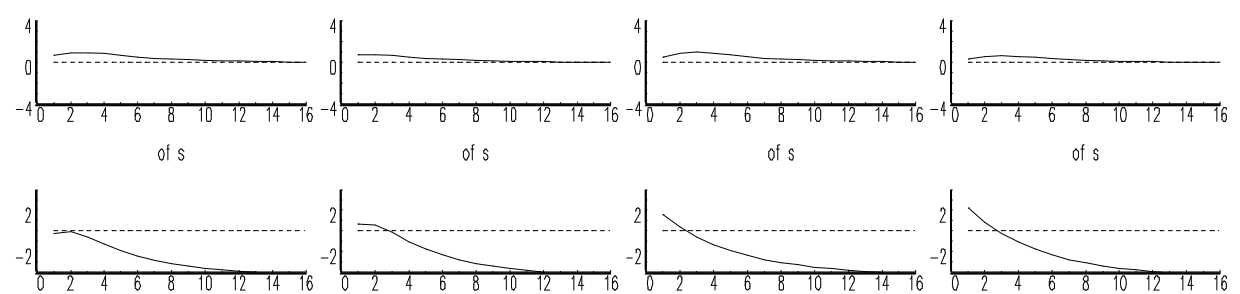

Figure 10. Flexible CPI inflation-targeting. IRF to a foreign inflation shock. In the first, second, third and fourth column, $\alpha^{i}$ and $\mu^{i}$ are equal, respectively, to $(0.05,0)$, $(0.05,0.5),(0.5,0)$ and $(0.5,0.5)$. 